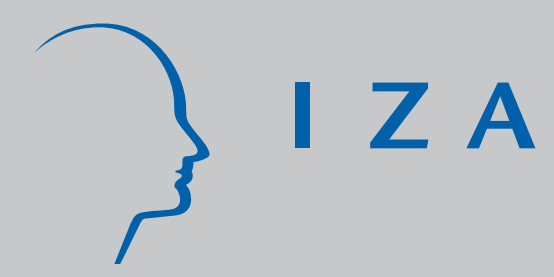

IZA DP No. 149

The Impact of Active Labor Market Programs and Benefit Entitlement Rules on the Duration of Unemployment

Rafael Lalive

Jan C. van Ours

Josef Zweimüller

May 2000 


\title{
The Impact of Active Labor Market Programs and Benefit Entitlement Rules on the Duration of Unemployment
}

\author{
Rafael Lalive \\ IEW, University of Zurich
}

Jan C. van Ours

CentER, Department of Economics, Tilburg University, CEPR, Institute for Labor Studies (OSA) and IZA, Bonn

Josef Zweimüller

IEW, University of Zurich, CEPR, London and IZA, Bonn

Discussion Paper No. 149
May 2000

\author{
IZA \\ P.O. Box 7240 \\ D-53072 Bonn \\ Germany \\ Tel.: +49-228-3894-0 \\ Fax: +49-228-3894-210 \\ Email: iza@iza.org
}

This Discussion Paper is issued within the framework of IZA's research areas The Welfare State and Labor Markets and Project Evaluation. Any opinions expressed here are those of the author(s) and not those of the institute. Research disseminated by IZA may include views on policy, but the institute itself takes no institutional policy positions.

The Institute for the Study of Labor (IZA) in Bonn is a local and virtual international research center and a place of communication between science, politics and business. IZA is an independent, nonprofit limited liability company (Gesellschaft mit beschränkter Haftung) supported by the Deutsche Post AG. The center is associated with the University of Bonn and offers a stimulating research environment through its research networks, research support, and visitors and doctoral programs. IZA engages in (i) original and internationally competitive research in all fields of labor economics, (ii) development of policy concepts, and (iii) dissemination of research results and concepts to the interested public. The current research program deals with (1) mobility and flexibility of labor markets, (2) internationalization of labor markets and European integration, (3) the welfare state and labor markets, (4) labor markets in transition, (5) the future of work, (6) project evaluation and (7) general labor economics.

IZA Discussion Papers often represent preliminary work and are circulated to encourage discussion. Citation of such a paper should account for its provisional character. 


\title{
ABSTRACT \\ The Impact of Active Labor Market Programs and Benefit Entitlement Rules on the Duration of Unemployment ${ }^{*}$
}

\begin{abstract}
Swiss policy makers created a unique link between unemployment benefits and Active Labor Market Programs (ALMPs) by making benefit payments conditional on program attendance after 7 months of unemployment duration. We evaluate the effect of Active Labor Market Programs and benefit entitlement on the duration of unemployment in Switzerland. In the evaluation we allow for selectivity affecting the inflow into programs. Our results indicate that

(i) After ALMP-participation the transition rate to jobs increases for Swiss women but not for Swiss men. However, the job hazard rate is strongly reduced during participation. Taken together, this leads to the conclusion that programs prolong unemployment duration for men, but tend to shorten durations for women.

(ii) Once the unemployment spell approaches the expiration of unconditional benefit entitlement the job-hazard rate increases strongly, both for women and for men.

(iii) There are important selectivity effects for Swiss females, but not for Swiss males.
\end{abstract}

JEL Classification: C14, C41, J64, I38

Keywords: Active labor market policy, benefit entitlement, treatment effect, bivariate duration model

Jan C. van Ours

CentER,

Tilburg University,

P.O. Box 90153

5000 LE Tilburg,

The Netherlands

Tel.: +31-13-4662316

Fax: $+31-13-4663042$

Email: vanours@kub.nl

\footnotetext{
* We thank M. Curti and J. Gast of the Swiss State Secretariat for Economic Affairs for help concerning the data and information on institutional details. For comments on earlier versions of the paper we thank seminar participants of the Workshop for Young Economists at ZEW, at IZA, the annual meeting of the population economics section of the German Economic Association, and in particular Wolfgang Franz, Michael Gerfin, Lorenz Goette, Michael Lechner, Patrick Puhani, Frank Reize, Viktor Steiner, Gerard van den Berg, and Rudolf Winter-Ebmer.
} 


\section{Introduction}

There is an increasing consensus among policy makers that actively assisting the unemployed in job search is preferable to simply providing them with passive income support. The danger is that reliance on passive income support may reduce work incentives and job-search activities and therefore increase the risk of long-term unemployment. Active labor market policies (ALMPs) are seen by many as the key to minimize these risks. Despite the agreed importance of ALMPs the success of the adopted programs has been rather mixed. One potentially important factor for the effectiveness of ALMPs may be the way in which benefit recipients are treated during the various stages of their unemployment spell. In particular, the obligations that go hand in hand with entitlement to unemployment insurance benefits (UIBs) and the degree to which these obligations are strictly enforced should be a determinant of the success of an ALMP-measure. As a result, many countries are discussing and/or implementing 'activity tests' to enhance the effectiveness of these measures.

The aim of the present paper is to study the impact of active labor market policies (ALMPs) on the duration of unemployment in Switzerland. The Swiss case is of interest because Switzerland has gone particularly far in activity testing by adopting new rules that link benefit eligibility closely to participation in ALMP-measures. According to the second revision of the national unemployment insurance act (AVIG), enacted in 1997, unemployed individuals are unconditionally entitled to UIBs only for a total of seven months. For an additional 17 months benefit payments are conditional upon participation in an ALMP-measure. After a 'framework period' of 24 months is expired, an individual has to rely on social assistance provided by local authorities.

As mentioned by the OECD (1996), the new Swiss unemployment insurance system is very ambitious and - from an international perspective unique. While other countries apply measures that require the unemployed to enter programs in order to be entitled to UIBs, the Swiss rules are different in two important respects. First, the intervention takes place at a rather early stage of the unemployment spell, after seven months. Secondly, UIB payments are strictly conditional upon ALMP-participation and this participation does not lead to a new (unconditional) benefit entitlement.

There are several other reasons why it is interesting to study the Swiss case. Switzerland has had a very distinct unemployment experience. The Swiss unemployment problem started not before the 1990s, which turned out as a decade of economic stagnation and increasing labor market problems. Before 1990, the Swiss labor market was a lucky island surrounded by high 
and persistent unemployment in most other European countries. The situation has changed in the early 1990s when the Swiss unemployment rate rose from $0.5 \%$ to $4.5 \%$ between 1990 to 1993 . Over the same period, the fraction of long-term unemployed increased from about $5 \%$ to $25 \%$. In 1997 the unemployment rate reached a high of $5.2 \%$ together with a share of long-term unemployed of more than $30 \%$. While these figures are still low by continental-European standards, their increase within a relatively short period of time raised the concerns of the public and policy makers. The reaction of the Swiss government was to introduce ALMPs on a rather large scale. It is per se interesting whether this policy has reached its goal to reduce the participants' unemployment duration. Moreover, in 1998 the unemployment rate went down to $3.9 \%$, from $5.2 \%$ in 1997, and this reduction coincided with the implementation of ALMP-measures on an economy-wide basis. It is therefore suggestive to ask whether the introduction of ALMP-measures could have contributed to the recent decrease in Swiss unemployment.

The question how participation in ALMP-measures affects labor market histories of individuals has been the subject of substantial debate over the last years. In this literature, the main problem usually concerns the possible endogeneity of ALMP-participation (See Heckman et al. (1999) for an overview of the economics and econometrics of ALMPs). The problem is that labor market outcomes for participants may be systematically different from non-participants for reasons (other than ALMP-participation as such) that are unobservable to the researcher. This is the well-known selection problem. In Switzerland, like in most European countries, but unlike in the U.S., randomized social experiments are uncommon, so one has to deal with nonexperimental data. With such data, the conventional procedure is to model the mechanism that determines selection into a training program together with the process of exit from unemployment.

To study the impact of ALMPs on unemployment duration the present paper employs the 'timing-of-events' method used in several studies. ${ }^{1}$ This approach is similar in spirit to the above mentioned conventional approach but goes beyond it in two important respects. First, while most of the literature is concerned with a binary treatment framework - participation yes or no - the 'timing-of-events' approach explicitly makes use of the information contained in the timing of the treatment. A treatment can be started at different points of time during an unemployment spell and variation in the timing of the treatment can be exploited to identify the (causal) treatment effect. Secondly, identification of the treatment effect does neither rely on

\footnotetext{
${ }^{1}$ See Van den Berg (2000) for an overview of duration models and in particular the use of these models in estimating treatment effects.
} 
a conditional independence assumption nor is it necessary to have a valid instrument. $^{2}$ Given that economic theory does not suggest a natural instrument, this is a particularly useful feature of this approach. To avoid biased estimates of the impact of ALMPs on unemployment durations it is necessary that individuals do not behave in anticipation to future events. If an unemployed worker knows that he will start to work in a job at a given future date he will decide not to enroll in a ALMP. For that reason the effect of that ALMP may be underestimated (example from Van den Berg (2000)). If unemployed workers have inside information on the future date of their entrance into an ALMP they may stop searching for a regular job. This may lead to overestimation of the effect of that ALMP. We return to this issue below when we consider the possibility of anticipation effects with respect to Swiss ALMP in more detail.

We use a new data set covering all entrants into unemployment in Switzerland over the four-months period $12 / 97$ until 03/98. The data come from administrative records and contain detailed information not only on a standard set of individual characteristics but also on the timing and duration of ALMPparticipation. The large sample size allows us to estimate the treatment-effect for different ALMP-measures and/or different sub-populations allowing for maximum interaction between the various explanatory variables. This is important since the various ALMP-measures are likely to have a different impact on different groups of individuals.

The plan of the paper is as follows. In the next section we describe the Swiss labor market policy in more detail and review previous studies on unemployment duration in Switzerland. In Section 3 we provide specific information on our data set and show some relevant descriptive statistics. Section 4 describes the methodology. The results of our analysis are presented in Section 5. Section 6 concludes.

\section{Labor market policy and unemployment du- ration in Switzerland}

Due to the absence of any serious unemployment problem, there was no need for a labor market policy in Switzerland in previous decades. Even compulsory unemployment insurance has not been introduced before the aftermath of the first oil shock which hit Switzerland particularly hard. Coverage was expanded further with the enactment of the national unemployment insur-

\footnotetext{
${ }^{2}$ The matching approach to evaluation invokes the conditional independence assumption (Heckman (1997) discusses the matching approach in detail).
} 
ance act (AVIG) in 1984. This law guaranteed a maximum entitlement to unemployment benefits of 50 weeks provided that one had been employed and had contributed to the insurance system for at least 6 months within the last year prior to the unemployment spell. Active labor market policy measures were practically non-existent.

When unemployment started to rise in the early 1990s, the government's initial reaction was the introduction of more generous rules of unemployment benefit eligibility. In 1992 and 1993 entitlement to unemployment benefits was increased successively to a maximum of 80 weeks. At the same time one needed to have been employed and contributed to the system still for at least 6 months, but now within the last 24 months prior to unemployment.

The second revision of the AVIG in 1995, enacted in 1997, constituted a radical change away from passive income maintenance towards active measures aiming at a rapid integration or reintegration of job seekers. The policy changes concerned both passive and active measures. On the passive side, entitlement to benefits was increased to a maximum of 24 months. One requirement to qualify for this maximum period was that the individual has been employed and had contributed for at the least 6 months within the 24 months prior to the unemployment spell. Furthermore, a job-seeker may decline a job-offer without loosing benefits, provided that the offered employment was not a 'suitable job'. An important part of the new law is a tighter definition of what is considered as 'suitable'. Work which pays 70 per cent of previous earnings is regarded as 'suitable' and has to be accepted by the job-seeker. Even a job that pays less than 70 per cent has to be accepted but then the individual can claim limited earnings support ('intermittent pay compensation'). Furthermore, the maximum period of benefit sanctions for uncooperative behavior has been increased from 40 to 60 days.

The most significant and ambitious change, however, took place on the active side. First, the new law lead to the creation of regional placement offices. The objectives of these offices is to provide services to both job seekers and employers. In particular, to keep a close contact with job-seekers and try to reintegrate them in a 'fast and lasting' way. Human resource consultants should be assigned between 75 and 150 unemployed and are expected to meet once a month for an in-depth personal interview with each job-seeker. This is rather ambitious and matched only by few other European countries (OECD, 1996, Curti, 1998).

Secondly, the new law obliged the Swiss cantons to supply a minimum number of ALMP-places per year. Economy-wide, these requirements add up to a stock of 25,000 places. This compares to an average stock of unemployment of about 188,000 individuals in 1997 and about 140,000 in 1998.

Thirdly, and certainly the most radical step, the new law created a close 
link between unemployment entitlement and participation in an active measure. For a newly unemployed the maximum entitlement period amounts to 104 weeks. This period of 104 weeks is divided into two different parts. For at most 7 months the job-seeker can receive UIBs, unconditional upon participation in an active measure. ${ }^{3}$ For the remaining 17 months UIBs are paid only if the unemployed is participating in a measure. ${ }^{4}$ After the 7 months of unconditional UIB-entitlement have been expired, an unemployed individual can be forced to enter an active measure, otherwise he or she looses the entitlement.

The above entitlement regulation holds for an individual who has been employed and has contributed to the insurance system for at least 6 within the last 24 months. For such a person a new 'framework period', amounting to 24 months of conditional and unconditional UIB-entitlement starts with the beginning of the spell. The situation is different for an individual who becomes repeatedly unemployed within that framework period. In that case, UIB-entitlement depends on the previous unemployment spell and UIB-history counts meaning that the new spell is treated as if the old unemployment episode would continue.

For obvious reasons, studies dealing with unemployment duration in Switzerland are scarce. Among the few papers focusing on the exit process from unemployment are Gerfin and Schellhorn (1995) who focus on the years 19911994 using data from the Swiss Labour Force Survey. Their findings indicate that older and less qualified individuals have a lower transition rate from unemployment to employment. No significant differences are found between men and women, as well as between Swiss and non-Swiss individuals but there are significant regional differences. They do not find negative duration dependence. In a recent study, Sheldon (1999) presents a comprehensive analysis of the Swiss unemployment change in the early 1990s. He finds that not only age and qualification but also the immigrant status are significant determinants of the exit rate from unemployment and concludes that the increase in the UIB-eligibility duration since 1990 may have significantly increased unemployment durations in Switzerland. ${ }^{5}$

\footnotetext{
${ }^{3}$ The maximum entitlement period is substantially longer for older workers whereas for younger job-searchers it amounts to 7 months.

${ }^{4}$ The actual application of this rule is not as rigid and mechanic. If no appropriate ALMP-slots are available for an unemployed worker whose unconditional entitlement is exhausted, the unemployed continues to receive benefits for a period of 80 days without participating in a measure.

${ }^{5}$ Currently, several groups of researchers - among them the authors of the present paper - are independently evaluating the impact of Swiss ALMP-measures. For a paper that uses the matching approach to estimate the effect of ALMPs, see Gerfin and Lechner (2000). In contrast to our paper, they do not focus on a possible impact of the particular Swiss
} 


\section{Data}

The data set from which we drew our sample, covers all unemployment entrants in Switzerland over the period December 1997 to March 1998 and follows these individuals up to the end of May 1999. These data come from administrative records of the State Secretariat for Economic Affairs (AVAMand ASAL-data base). Among the 41,725 Swiss workers (24,127 males, 17,598 females) who started an unemployment spell during the above period we concentrate our empirical analysis on a subsample of those workers who (i) were eligible to unemployment benefits and (ii) for whom we could match the information of the AVAM- and ASAL-data base with information from social security records (AHV-data). ${ }^{6}$ The latter provide detailed information on the individuals' earnings and employment history over the last 10 years prior to the unemployment spell. This subsample contains 8,427 Swiss men and 5,462 Swiss women. To get a more homogeneous sample we excluded 402 male (1,548 female) part-time workers ('partly unemployed' because entitled to collect some benefits), 122 male (79 female) disabled workers, 426 males (116 females) with unreliable earnings data, and 33 females previously employed in the construction sector. The sample on which our empirical estimates are based contains 7,477 Swiss men and 3,686 Swiss women.

\section{Table 1}

Apart from detailed information on the duration of unemployment, the timing and duration of ALMP-attendance and the individuals' earnings- and employment history, the data provide information on various individual characteristics like gender, age, family status, number of dependents, skill level, type of last job, as well as on the unemployed's region, industry, and occupation. Most interestingly for the purpose of the present study, the data also contain information on the duration of unconditional benefit eligibility for all unemployment entrants, as measured at the date of unemployment entry. Table 1 presents descriptive statistics on a subset of variables used in the subsequent analysis, separately for participants and non-participants (see Tables A1a and A1b in the Appendix for descriptive statistics on all variables). To account for the heterogeneity in the various ALMP-measures we split the group of participants into those attending training courses and those enrolled in employment programs. As can be seen from Table 1, nonparticipants, course-participants and participants in employment programs

entitlement rules.

${ }^{6}$ We had only limited to access to the social security records. The matching of social security data with the unemployment files was random. 
differ substantially with respect to various characteristics. For both males and females, participants in employment programs tend to be older, lower skilled, less easily employable and earned a lower wage in their last job than non-participants. Participants in courses are also older, but are better (males) or equally well (females) skilled and employable, and earn a higher wage than non-participants.

\section{Figure 1a, 1b}

Figure 1 shows the empirical hazard rate for the various processes under consideration. For Swiss males, the job hazard rate is increasing in the initial stage of the unemployment spell and reaches a high of $14 \%$ after a duration of 3 months. Thereafter the hazard rate decreases and falls below $5 \%$ for the long-term unemployed. The picture is qualitatively and quantitatively similar for Swiss women. The job-hazard rate first rises, reaches a peak of about 14 $\%$ after the first 2 months, then decreases continually and falls to $5 \%$ and below for the long-term unemployed. Both for males and for females, the empirical entry-rates to ALMP-courses have a shape similar to the job-exit rate, but at a lower level. The picture is less clear for employment programs where, for males and females, the empirical hazard rate varies relatively little with duration.

\section{Figure 2}

Figure 2 shows the job-hazard rate against the time since unconditional benefit eligibility has expired. (On the horizontal axis a negative number $-t$ means that an individual is still unconditionally eligible for $t$ months, a positive number $t$ means that unconditional benefit eligibility has expired since $t$ months). For both, men and women the hazard rate increases with a shorter remaining unconditional benefit eligibility duration. Note that the shape of the job-hazard rate in Figure 2 mixes up an impact of benefit eligibility rules with possible negative duration dependence (as suggested in Figure 1). This may explain why at higher durations the exit rates decrease again. Nevertheless, Figure 2 shows that the impact of benefit eligibility rules may be of substantial importance in the explanation of job-finding rates.

The various ALMP-measures supplied by the regional placement offices can be divided into five broad categories: (i) courses to improve basic skills (aiming at improving the effectiveness of individual job search and selfesteem), (ii) language courses (including reading and writing skills), (iii) computer courses (basic word processing and spreadsheet calculation), (iv) 
other course (a rather heterogeneous group of course types ${ }^{7}$ ), and (v) employment programs.

\section{Table 2}

Table 2 shows the distribution of the 2,398 ALMP-participants in our sample across these broad categories of ALMP-measures. We examine the effect of the first ALMP an unemployed entered which lasted for at least one week. We will present additional results on the impact of attending a second program on unemployment duration in Section 5.2.

Courses to improve basic skills make up more than a third of all measures, somewhat more than $20 \%$ are enrolled in employment programs. The categories computer courses and 'other courses' account for somewhat more than $30 \%$ and language courses for about $10 \%$. There are important differences between men and women. Women are more frequently enrolled in computer courses and language courses, whereas men are more often found in employment programs and other courses. Basis courses and computer courses are on average shorter than one month whereas language courses and, in particular, employment programs tend to last quite long. About $20 \%$ of the courses were still in progress at the end of our observation period (May 1999). There is some variation in the timing of ALMP-entry. In general, short courses are attended earlier, longer measures are attended at a later stage of the unemployment spell.

\section{The empirical model}

In order to establish the treatment effects of ALMP-programs on the exit rate from unemployment to a regular job we have to set-up a model that accounts for possible selectivity in the inflow into the programs. For this we use a multivariate duration model. Generally, in multivariate duration models the variation in the durations at which treatment is administered to individuals, and data on the corresponding pre- and post-treatment durations can be exploited to identify the treatment effect. A formal proof of this is given in Abbring and Van den Berg (1998). Van den Berg (2000) presents an overview of duration models and has a general discussion on the use of duration models in estimating treatment effects.

\footnotetext{
${ }^{7}$ They include specific computer training, business administration, technical training, courses in the tourism and the health sector - this is a group of very heterogeneous, but each quantitatively small programmes.
} 
In previous studies sometimes 'treatment' has been modeled as a separate labor market state. Gritz (1993) for example considers the impact of training on the employment experience of American youths and Bonnal, Fougère and Sérandon (1997) study the effect of public employment policies set up in France during the 1980's. Both studies deal with the potential selectivity of the inflow into the treatment state by allowing related unobserved heterogeneity terms to affect both the inflow into treatment and the inflow into other labor market positions.

In our study we do not treat ALMPs as a separate state. We assume that the job finding rate shifts to another level at the moment a worker enters an ALMP, a shift Gritz (1993) calls an 'incidence effect'. ${ }^{2}$ Similar models like ours have been estimated in several studies. Examples are Abbring, Van den Berg and Van Ours (1997) and Van den Berg, Van der Klaauw and Van Ours (1998). In these studies the effect of benefit sanctions on the transition rate from unemployment to employment is modeled. Here too, the issue of selectivity is very important. Selectivity is accounted for by modeling both the job finding rate and the rate by which unemployed get a sanction imposed and allowing for correlation between the unobserved heterogeneity terms in both transition rates. Both studies find a significant positive effect of benefit sanctions on the transition rate from unemployment to a job. In the study by Van den Berg, Van der Klaauw and Van Ours (1998) it is shown that if unobserved heterogeneity is not accounted for, no effect of sanctions is found. ${ }^{9}$

Other examples are Lubyova and Van Ours (1999) and Van Ours (2000) in which the system of ALMPs in the Slovak Republic is investigated. The treatment system consists to a large extent of the creation of temporary subsidized jobs and of retraining unemployed workers. Lubyova and Van Ours (1999) find that selectivity is important. If in the estimation selectivity is not accounted for a negative effect of treatment on the transition from unemployment to a regular job is found. If selectivity is accounted for, treatment has a positive effect on the transition from unemployment to a regular job. Van Ours (1999) extends this analysis by also examining the job separation rates for those unemployed that find a job after having entered an ALMP. He finds that it is important to account for initial selectivity of the inflow

\footnotetext{
${ }^{8}$ As discussed below, we distinguish between a 'during treatment' and an 'after treatment' effect. That is, we consider a possible shift of the transition rate from unemployment to a regular job at the moment a worker enters a program and at the moment he or she leaves the program. Furthermore, we investigate whether or not the 'after treatment' effect is duration dependent.

${ }^{9}$ A related study is Holm, Van den Berg and Van Ours (1998). In this study it is investigated whether temporary jobs help medical students to become a medical specialist.
} 
into ALMP.

We start with a simple specification in which the transition rates are not affected by the presence of unobserved heterogeneity components. In this baseline model we assume the different transition rates to be uncorrelated. Later on, we introduce unobserved heterogeneity components in the different transition rates where we allow these terms to be correlated. This way we account for possible selectivity in the entrance into ALMPs.

Our baseline model has proportional hazards with a flexible baseline. We distinguish three transition rates, from unemployment to a regular job, from unemployment to a training program (course) and from unemployment to an employment program. Programs are not considered to be separate states, but once an unemployed worker enters a program there is a shift in the transition rate from unemployment to a regular job. Once the unemployed leaves the program there is again a shift in the job finding rate.

Apart from the treatment effects we are also interested in the possible effects of the exhaustion of benefit payments that are not conditional on ALMP-participation. Workers who are confronted with benefit exhaustion may change their behavior before this exhaustion actually occurs. To account for possible anticipation effects, we investigate whether 1 month before benefit exhaustion there is already an effect on the job finding rate. We also investigate the effect 1 month after and more than 1 month after potential benefit exhaustion. ${ }^{10}$

First, we consider the transition from unemployment to regular jobs. Differences between unemployed individuals in the transition rate from unemployment to a job can be characterized by the observed characteristics $x$, the elapsed duration of unemployment itself, and a variable indicating whether or not the individual started in program $p(p=$ course, employment program). Let $t_{p s}$ be the time at which the individual starts participating in program $p$ and let $t_{p e}$ be the time at which the individual ends program $p$. Furthermore, let $I\left(t_{p s}<t \leq t_{p e}\right)$ be an indicator variable for participation in program $p$ and let $I\left(t_{p e}<t\right)$ be an indicator variable for after program participation. ${ }^{11}$ Finally, let $d_{z}$ be an indicator of benefit exhaustion $(z=1$ month before, 1 month after, more than 1 month after benefit exhaustion. Then, the transition rate from unemployment to a job at time $t$ conditional on $x, t_{p s}, t_{p e}$ and $d_{z}$ can be specified as follows:

\footnotetext{
${ }^{10}$ Note that we able to identify this effect because not every individual has the same potential benefit period. If that was the case we would not be able to distinguish the benefit exhaustion effect from the effect of duration dependence.

${ }^{11}$ The indicator variables have a value of 1 if the expression is true and a value of 0 if not true.
} 
$\theta_{u}\left(t \mid x, t_{p s}, t_{p e}, d_{z}\right)=\lambda_{u}(t) \cdot \exp \left(x^{\prime} \beta_{u}+\delta_{p} \cdot I\left(t_{p s}<t \leq t_{p e}\right)+\delta_{p e} \cdot I\left(t_{p e}<t\right)+\mu_{u z} \cdot d_{z}\right)$

where $\lambda_{j}(t)$ represents individual duration dependence, $\delta_{p}$ measures the instantaneous effect that participation in program $p$ has on the transition rate from unemployment to a regular job and $\delta_{p e}$ measures the after-treatment effect of program $p$. Furthermore, $\mu_{u z}$ measures whether there is any benefit exhaustion effect. We model flexible duration dependence by using a step function

$$
\lambda_{u}(t)=\exp \left(\Sigma_{k}\left(\lambda_{u, k} \cdot I_{k}(t)\right)\right.
$$

where $k(=1, . ., 4)$ is a subscript for time-intervals and $I_{k}(t)$ are time-varying dummy variables that are one in subsequent time-intervals. We distinguish four time intervals: 1-3 months, 3-6 months, 6-12 months and 12 and more months. Because we also estimate a constant term, we normalize $\lambda_{u, 1}=0$.

The basic assumption in our baseline model is that the inflow into the program is a random process in the sense that it is independent of the process by which unemployed find jobs. The selection into the program is exogenous and does not depend on unobserved characteristics that also affect the job finding rate. In other words, conditional on observed characteristics and the duration of unemployment the quality of the unemployed flowing into a program is as good (or as bad) as the quality of the unemployed that remain unemployed. Then, if we measure an effect of program $p\left(\delta_{p} \neq 0\right.$ or $\left.\delta_{p e} \neq 0\right)$, this is a 'true' effect. This effect could go both ways. If for example $\delta_{p}<0$ the program has a negative instantaneous effect on the re-employment hazard, which could imply that during the program the unemployed worker looks for a job with a smaller search intensity. If for example the after-treatment effect is smaller than zero, this could be caused by stigmatization. If $\delta_{p e}>0$ the program participants have a higher (after-program) transition rate to a job than the non-participants have, an effect that could be due to an increase in human capital. Note that in the specification of the hazard in equation (1) the after-treatment effect of a training program also occurs immediately.

The density of realized unemployment durations $t_{u}$ is simply:

$$
f_{u}\left(t_{u} \mid x, t_{p s}, t_{p e}, d_{z}\right)=\theta_{u}\left(t_{u} \mid x, t_{p s}, t_{p e}\right) \exp \left(-\int_{0}^{t_{u}} \theta_{j}\left(s \mid x, t_{p s}, t_{p e}\right) d s\right)
$$

In a similar way we model the transition rate to program $p$ at time $t$ conditional on $x$ and $d_{z}$ as: 


$$
\theta_{p}\left(t \mid x, d_{z}\right)=\lambda_{p}(t) \exp \left(x^{\prime} \beta+\mu_{p z} \cdot d_{z}\right)
$$

where $\lambda_{p}(t)=\exp \left(\Sigma_{k}\left(\lambda_{p, k} \cdot I_{k}(t)\right)\right.$ and the normalization is $\lambda_{p, 1}=0$. The density of realized durations of "search" $\mathrm{t}_{p}$ for program $p$ is equal to:

$$
f_{p}\left(t_{p} \mid x, d_{z}\right)=\theta_{p}\left(t_{p} \mid x, d_{z}\right) \exp \left(-\int_{0}^{t_{p}} \theta_{p}\left(s \mid x, d_{z}\right) d s\right)
$$

In our extended model we allow for unobserved heterogeneity to affect the transitions to both a job and to a program:

$$
\begin{aligned}
\theta_{u}\left(t \mid x, t_{p s}, t_{p e}, d_{z}, u\right) & =\lambda_{u}(t) \cdot \exp \left(x^{\prime} \beta_{u}+\delta_{p} \cdot I\left(t_{p s}<t \leq t_{p e}\right)+\delta_{p e} \cdot I\left(t_{p e}<t\right)+\mu_{u z} \cdot d_{z}+u\right) \\
\theta_{p}\left(t \mid x, d_{z}, v_{p}\right) & =\lambda_{p}(t) \exp \left(x^{\prime} \beta_{p}+\mu_{p z} \cdot d_{z}+v_{p}\right)
\end{aligned}
$$

where $u$ and $v_{p}$ are the components of unobserved heterogeneity in the transition rates to a regular job and to program $p$. Now we can allow for selectivity in the inflow into a program. If the unobserved characteristics have a negative effect on the job finding rate and a positive effect on the transition rate to a program, then conditional on the observed characteristics and the elapsed duration of unemployment the average quality of the workers in a program is lower than the average quality of workers who do not enter a program. Then, if we would simply compare the transition rates to regular jobs of both groups we would compare workers with unfavorable characteristics and program participation with workers with more favorable characteristics and non-participation. Therefore, we would underestimate the true effect of participating in a program. The opposite effect is also possible. One could imagine that the people in control of the programs want their programs to be a success. Therefore they prefer workers with good characteristics to flow into their program. This would imply that there is a positive correlation between the unobserved heterogeneity components in both transition rates. Then, we would overestimate the treatment effect of programs.

We define $G\left(u, v_{p}\right)$ to be the joint distribution of the unobserved characteristics $u, v_{p}$. Then, the joint density function of $t_{u}, t_{p}$ conditional on $x, t_{p s}$, $t_{p e}$ and $d_{z}$ equals

$$
f_{u, p}\left(t_{u}, t_{p} \mid x, t_{p s}, t_{p e}, d_{z}\right)=\int_{u} \int_{v_{p}} f_{u}\left(t_{u} \mid x, u, t_{p s}, t_{p e}, d_{z}\right) f_{p}\left(t_{p} \mid x, v\right) d G\left(u, v_{p}\right)
$$

We assume $G$ to be a multivariate discrete distribution of unobserved heterogeneity. Work by Heckman and Singer (1984) suggests that discrete 
distributions can approximate any arbitrary distribution function $G$. We assume that each transition rate has two points of support $\left(u_{a}, v_{p, a}\right),\left(u_{b}, v_{p, b}\right)$. The associated probabilities are denoted as follows ${ }^{12}$ :

$$
\begin{array}{ll}
\operatorname{Pr}\left(u=u_{a}, v_{p}=v_{p, a}\right)=p_{1} & \operatorname{Pr}\left(u=u_{a}, v_{p}=v_{p, b}\right)=p_{2} \\
\operatorname{Pr}\left(u=u_{b}, v_{p}=v_{p, a}\right)=p_{3} & \operatorname{Pr}\left(u=u_{b}, v_{p}=v_{p, b}\right)=p_{4}
\end{array}
$$

where $0 \leq p_{i} \leq 1, i=1, . ., 4$. We model $p_{i}=\exp \left(\alpha_{i}\right) /\left(1+\sum_{i} \exp \left(\alpha_{i}\right)\right)$, normalizing $\alpha_{4}=0$, to have a multinomial logit specification. The set-up of the likelihood is similar to the one presented in equation (6). However, because of the introduction of unobserved heterogeneity it is not possible to factorize the likelihood.

\section{Estimation results}

In the following subsection 5.1 we will discuss the effect on the transition rate from unemployment to a job of the first attended ALMP-measure that lasts longer than one week ${ }^{13}$. In all cases, we provide separate estimates for men and women.

Subsection 5.2 deals with several extensions and sensitivity tests for the results of our basic specification. We will discuss (i) the impact of the second attended measure, (ii) the possible impact of a lower job hazard rate between course assignment and start of the course, (iii) more sophisticated specifications of the correlations between the various processes, (iv) the impact of distinguishing separate transition rates to each of the five ALMP programs, (v) the possible duration dependence of the after program treatment effect and (vi) the possible occurrence of anticipation effects.

Subsection 5.3 presents the results of some simulations, which give an idea of the magnitude of the treatment effects.

\subsection{Parameter Estimates}

Table 3 displays the estimated treatment effects and the estimated effects of benefit entitlement rules on the transition rates to a regular job for Swiss males and Swiss females. Results using the univariate model (columns 1 and

\footnotetext{
${ }^{12}$ Note that this specification implies that we assume that there is perfect correlation between the unobserved heterogeneity terms of the labor market programs.

${ }^{13}$ We assume that shorter treatments have no impact on the exit process from unemployment.
} 
3) and the selectivity model (columns 2 and 4) are reported. This allows us to discuss the impact of accounting for selectivity on the estimated treatment effects.

Treatment effects and selectivity. For Swiss males, the results in Table 3 draw a negative picture of the success of the ALMP-measures (column 1 in Table 3). We estimate a strong reduction in the job hazard during participation meaning that most ALMP-attendants do not leave before the measure ends. The shift is of almost equal size in all five broad ALMPcategories. The effect of primary interest, the change in the job-hazard rate after ALMP-participation, shows that for Swiss males the corresponding programs were not particularly successful. While the point estimate is positive for four out of the five broad ALMP-measures, none of the effects is significantly different from zero. We cannot reject the hypothesis that participation in these programs had no impact on transitions to a regular job for Swiss males. Using a Likelihood-Ratio test, which compares the model in Table 3 column 1 (with likelihood $L_{U}$ ) with a model where all five treatment effects after participation are put to zero (with likelihood $L_{R}$ ), yields a test statistic $-2 \ln \left(L_{R} / L_{U}\right)=3.19$. This is clearly below the critical value of $\mathcal{X}^{2}(5)$ $=11.07$.

The second column of Table 3 contains the results for Swiss males once we allow for selectivity in the inflow into ALMPs. The estimated parameters of the unobserved heterogeneity distribution (masspoints and probabilities in column 2 of Table 3) indicate that for unemployed Swiss males unobserved components $\left(u, v_{c}, v_{e}\right)$ of the job-hazard and the two ALMP-entry rates can be characterized by a distribution with two points of support. ${ }^{14}$ The first group, indicated by superscript $a$, (77 \% of the population) has a relatively low job-hazard rate $\left(u^{a}=-4.05\right)$, a relatively high entry rate into courses $\left(v_{c}^{a}=-2.32\right)$, and a relatively high entry rate into employment programs $\left(v_{e}^{a}=-4.01\right)$. The second group, indicated by superscript $b,(23 \%$ of the population) has a relatively high job-hazard rate $\left(u^{b}=-3.45\right)$, a relatively low entry rate into courses $\left(v_{b}^{c}=-5.98\right)$, and will never enter an employment program $\left(v_{e}^{b}=-\infty\right)$. This means, the results in column 2 of Table 3 indicate that there is negative selection: Conditional on observed characteristics and elapsed unemployment duration, the inflow into ALMPs has worse job prospects that those who do not enter. As a result of this negative selection, the estimated treatment effects, both during and after participation, are now larger (or less negative). However, accounting for selection on the basis of

\footnotetext{
${ }^{14}$ The estimated model allowed for four points of support of the joint distribution of $\left(u, v_{c}, v_{e}\right)$. In the estimation it turned out that two points of support suffice.
} 
unobserved heterogeneity does not lead to a strong improvement in the loglikelihood. Moreover, according to the Akaike (1973) Information Criterion (AIC), the selectivity model performs worse than the univariate model. For Swiss males, we therefore have to reject the selectivity model. ${ }^{15}$

For Swiss females the results are different (column 3 in Table 3). With the exception of language and other courses, we find that the reduction in the job hazard during participation is considerably smaller for Swiss women than for Swiss men. The most significant difference, however, shows up in the effect after treatment. With the exception of language courses, we find a significant improvement in the job chances for Swiss females in all broad ALMP-categories as a result of ALMP-participation. A joint test of all five after participation effects reveals that ALMPs significantly increase the job-hazard for Swiss females at any conventional level of significance $\left(-2 \ln \left(L_{R} / L_{U}\right)=386.10\right)$. This is clearly above the critical value at conventional levels of significance. For computer courses and other courses we find that the increase in the job hazard rate is quantitatively important. The impact is even stronger for women enrolled in employment programs.

Column 4 in Table 3 presents the corresponding results that correct for selectivity. Similar to Swiss males, we estimate that the unobserved heterogeneity distribution for Swiss females has two points of support. The first group, indicated by superscript $a,(18 \%$ of the population) has a relatively low job-hazard rate $\left(u^{a}=-4.07\right)$, a relatively low course-entry rate $\left(v_{c}^{a}=-4.12\right)$ and a relatively high entry rate into employment programs $\left(v_{e}^{a}=1.76\right)$. The second group, indicated by superscript $b$, ( $82 \%$ of the population) has a relatively high job-hazard rate $\left(u^{b}=-2.47\right)$, a relatively high course-entry rate $\left(v_{c}^{b}=-4.06\right)$ and will never enter an employment program $\left(v_{e}^{b}=-\infty\right)$. This means we have strong negative selection into employment programs, but positive selection into courses (which is weak since $v_{c}^{a}-v_{c}^{b}$ is small). Again it is interesting to look at the consequences of accounting for unobserved heterogeneity for the estimated treatment effects. The change in the course-treatment effects is minor. This is not surprising given that selectivity is weak. The change in the treatment effect for employment programs, however, is substantial. The treatment effect during participation changes from negative to positive, and the after-treatment effect increases strongly.

\footnotetext{
${ }^{15}$ We cannot use a conventional likelihood ration test, because the probability parameter lies on the border of the parameter space in the model without heterogeneity. Instead, we use the Akaike (1973) Information Criterion $(A I C)$. Denote by $L_{A}$ the value of the likelihood function at the maximum for a model $\mathrm{A}$ and by $P_{A}$ the number of parameters of this model. Then the criterion is $\operatorname{AIC}(A)=-2 \ln \left(L_{A}\right)+2 P_{A}$. The preferred model minimizes the AIC. In other words, a parameter should be added only if the log likelihood increases by more than one unit.
} 
Not taking into account unobserved heterogeneity, we compare job-exit rates of non-participants (which have better job prospects) to the exit-rates of participants (with worse prospects). By accounting for unobserved heterogeneity we net out the heterogeneity component. The result is a larger estimate for the treatment effect.

In sum, our results are threefold. First, ALMP-participants have a lower exit rate, because program-attendance is time-consuming and leads to a lower search intensity during participation. This effect is rather robust and, in general, does not depend on whether or not we account for selectivity. This effect tends to prolong the duration of unemployment. Second, we find that there is no impact of participation after the end of the program for men, but a strong impact of almost all programs for women. Finally, selectivity is important for females but unimportant for males.

Accounting for the activity test. As mentioned in section 2, the Swiss unemployment system creates a strong link between UIB-entitlement and ALMP-participation. A 'typical' individual who starts a new 'framework period' is entitled to benefits without ALMP-participation for the first 7 months of an unemployment spell. Thereafter, an unemployed is only entitled if he or she attends a program. If all individuals were 'typical', the impact of the entitlement rules could not be distinguished from duration dependence. To identify such an effect, there has to be variation across individuals in the point of time when further UIB-entitlement requires mandatory attendance of some ALMP-measure. Such variation may come from two sources. First, there are exceptions from the above rule if individuals meet certain characteristics. For instance, older individuals are unconditionally entitled for more than 7 months. Second, for those individuals who have become repeatedly unemployed within a short time, the current unemployment spell is viewed as a continuation of the last spell. This means, unconditional entitlement duration is lower for those individuals.

\section{Figure 3}

Figure 3 shows the distribution of unconditional benefit eligibility duration at the start of the unemployment spell both for men and for women. The spikes around month seven indicate the situation for the 'typical' individual. Apart from these spikes there is substantial variation both below and above 7 months of unemployment duration. As a consequence we can separate a possible effect of the benefit entitlement rules from the duration dependence effect. 
Obviously, an individual who wants to avoid being forced into a program may search harder before unconditional UIB-entitlement has expired. As indicated in the previous section, to test for such entitlement effects we allow the job-hazard rate to shift already one month before the expiration date. Moreover, we allow the job-hazard rate to shift after expiration of unconditional entitlement to see whether the activity test leads to a higher search effort of workers after the unemployment spell has reached the stage of mandatory ALMP-attendance.

Our results present a clear picture: the Swiss unemployment benefit entitlement rules tend to increase the transition rates from unemployment to a regular job. For Swiss men, the hazard rate starts to increase already before the expiration of unconditional benefit entitlement and stays at that level during the month of expiration. Thereafter there is a strong further increase in the transition rate to a regular job. Also for Swiss women, we see an increase in the job transition rate, which starts during the month of benefit expiration and stays at a slightly lower level thereafter. These 'activity' rules therefore tend to reduce the duration of unemployment. It seems that the requirement to participate in an ALMP-measure makes further unemployment significantly more unattractive for unemployed individuals. As a result they search harder for jobs and are more willing to accepted job offers once ALMP-participation becomes a requirement for further benefit entitlement.

It is also interesting to take a look at the impact of entitlement rules on the entry-rates to ALMP-measures (Table 4). If the rules were strictly enforced we would expect a very strong increase in the ALMP-entry rate, both to courses and to employment programs, after expiration of unconditional entitlement. We find positive and significant effects in all selection processes. For Swiss men, entry into programs increases significantly during the month of exhaustion and stays at about this level thereafter. For Swiss women, we find the strongest increase in the course-entry rate during the month when unconditional benefits expire and a somewhat smaller (but still higher than in the early stage of unemployment) increase thereafter. Entry rates to employment programs increase relatively strongly for Swiss women.

While we find a significant increase in ALMP entry-rates when eligibility becomes conditional upon ALMP-participation, there is no evidence for a situation where all individuals who approached exhaustion have to enter a program in order to gain further entitlement. There are two reasons for this. First, ALMP-participation during the first seven months leads to delay the period when UIB payment become activity tested. This means that the date of UIB-expiration at the start of the unemployment spell does not coincide 
with actual expiration. ${ }^{16}$ Secondly, and perhaps more importantly, whether or not an individual will actually be forced to enter a program does also depend on the supply of measures. Our results indicate that the regional employment offices apparently are not in a position to provide the supply of ALMP slots to all unemployed whose unconditional benefit eligibility has run out. Individuals for whom no such slot can be supplied are entitled to a limited duration (80 days) of further UIB payments.

Duration dependence. The results in Table 3 account for possible duration dependence by allowing the two hazard rates to shift over time. For Swiss males the estimated exit rate from unemployment starts at a relatively low level and reaches its high during the interval 3 to 6 months of unemployment. Thereafter, there is negative duration dependence. For Swiss males, the job hazard is surprisingly low in the first 3 months of the unemployment spell compared to the months 4 to 6 . This may be due to seasonality. We consider the inflow from December 97 to March 98. For the average individual in the sample, the first months of the spell is therefore characterized by a small outflow for seasonal reasons. Moreover, a high $23 \%$ of the inflow originally worked in the construction sector.

Also the duration dependence pattern is somewhat different for Swiss females as compared to Swiss males. As far as the job-finding rate is concerned, we do not find a significant impact of duration during the first 6 months of the unemployment spell. Thereafter there is strong negative duration dependence.

\subsection{Sensitivity Analysis}

In order to investigate the sensitivity of our results we have extended the analysis in a number of ways. ${ }^{17}$ First, we investigated whether there is an impact of the second attended program. We find that the estimated effects of second programs on the transition rates from unemployment to a job are very much the same as those of first attended programs. During the program the job finding rate is smaller and after the program, the job finding rate increases. For males the during-effect is significantly negative for all but

\footnotetext{
${ }^{16}$ This means that for a small proportion of our sample - those who entered an ALMP and participated already before unconditional benefits expire (10\% of the sample) - we underestimate unconditional benefit eligibility duration.

${ }^{17}$ We only discuss the treatment effects, since in all estimations it turned out that the impact of benefit-exhaustion was very similar to the one estimated in the baseline model of Table 3.
} 
one program ${ }^{18}$, while the after-effect is significantly positive for other courses and employment programs. For females, the during-effect is negative, though not significantly different from zero. The after-program effect for females is significantly positive for computer courses and employment programs. In the context of our model this implies that for females participating in several programs might be worthwhile. ${ }^{19}$

\section{Table 5}

We also investigated what happened during the period of time between the moment that workers where informed about the course they had to attend and the start of the course. In an experimental study in Kentucky, Black et al. (1998) find that unemployed who find out about mandatory program obligations leave unemployment rather quickly. In fact the differences in the job finding rate between unemployed that are assigned to a mandatory employment or training program and other unemployed is the pre-program effect rather than the effect of the actual receipt of employment and training services. Our investigation shows that this effect does not occur in Switzerland. It turns out that no individual left unemployment between the assignment date and the start of an ALMP-program. As part of the sensitivity analyses we re-estimated both the baseline and the extended model using the assignment date as start of the program, but this did not affect the results concerning the treatment effects a lot. ${ }^{20}$

Furthermore, we investigated whether more sophisticated specifications of the correlations between the various processes was relevant. In particular, we estimated a model that allowed for the entrance into both types of programs to be less than perfectly correlated through the unobserved components. We did this by trying to estimated a multivariate discrete distribution with eight points of support. However, we could not estimate additional points of support. The distribution in our extended model with four points of support seems to be sufficiently flexible.

We also analyzed to what extent our results change if instead of estimating transitions to two broad types of ALMP-programs we distinguish separate transition rates to each of the five ALMP programs. We found that these hardly affected the results with respect to the treatment effects.

\footnotetext{
${ }^{18}$ For language courses that were the second program there are insufficient observations about transitions to a job to estimate the treatment effect.

${ }^{19}$ There are not sufficient observations to investigate whether particular combinations of programs are more beneficial than other combinations.

${ }^{20}$ In fact only the during-program effect changed because this now included the period between assignment and start of the program.
} 
Furthermore, we tried to investigate whether the introduction of three mass-points instead of two changed the estimation results. However, we were not able to find a third point of support in the discrete heterogeneity distribution.

We then investigated possible duration dependence of the after program treatment effect (see Table 5, lower panel). We did this by making a distinction between the treatment effects less than 2 months after the program and the treatment effects more than 2 months after the program. We could not reject the hypothesis that both types of treatment effects are similar. The treatment effect does not seem to be duration dependent, at least not in the short period of time we consider.

Finally, we investigated the relevance of possible anticipation effects concerning the start of an ALMP. As Van den Berg (2000) indicates the timing of events approach requires that the unemployed do not anticipate the start of the treatment. They may know the determinants of the transition rate into the treatment state but may not know the exact time when their treatment starts. Such knowledge would cause the individuals to behave accordingly already before the treatment. There are several reasons why such anticipation effects are not significant in the case of Swiss ALMP-programs. First, the time between assignment to a specific program and the actual start of the program is usually short, in the range from one to two weeks. Second, an unemployed worker cannot just start at any program. There has to be a vacant slot and if there is one, there has to be a match between the slot and the persons involved. There is also competition between unemployed workers for vacant slot. Nevertheless as part of our sensitivity analysis we investigate to what extent possible anticipation effects may bias our results. We performed two types of sensitivity analyses with respect to possible anticipation effects. First, we analyzed a subsample only including unemployed that were entitled to 7 months of initial benefits. For this sample we estimated a model where all durations beyond 5.5 months were treated as right-censored. So, we only use information over a period of time when anticipation effects are not really important. For training courses we found similar results as presented in Table $3 .{ }^{21}$ Second, we introduced a new variable that indicates the probability that an unemployed in a particular Canton is assigned to an ALMP. ${ }^{22}$ This variable was introduced in all processes and was interacted

\footnotetext{
${ }^{21}$ For employment programs we could not estimate an after-treatment effect because of lack of observations.

${ }^{22}$ This variable is defined as the logarithm of the ratio of the number of participants in ALMP-programs divided by sum of the number of those who exhausted benefits plus the number of participants in ALMPs for each canton (there are 26 cantons in Switzerland). It is measured at the start of the unemployment spell and indicates to what extent an
} 
with the after-participation treatment effects. We found that this 'anticipation' variable does not affect the transition rates. It does have some effect on the after-treatment effects of employment programs for males and the after-treatment effects of other courses for females. However, the size of the effects is small. Therefore, on the basis of both types of sensitivity analysis we conclude that anticipation effects are not important.

\subsection{Simulations}

To get an idea about the magnitude of the treatment effects we perform some simulations. The treatment effect of a program consists of two parts. First, there is the during program effect that is negative in many cases because apparently unemployed reduce their search efforts while being on a program. The second effect is the after program treatment effect that is sometimes but not always positive. So, individuals that participate first have a lower job finding rate and then have a higher job finding rate than individuals that do not participate in a program. On the basis of our estimation results we can calculate a "break-even" duration of the ALMP-programs, that is the duration at which the cumulative exit probability of participants and nonparticipants is the same. Once the unemployment spell goes beyond this duration the participant is better off than a non-participant. However, until that moment the non-participant is better off. Table 6 shows the results of our calculations.

\section{Table 6}

For Swiss males, it takes rather long until the negative effect during treatment is compensated by the positive effect after treatment. Computer courses have the lowest break even duration; it takes 11.0 months until the survival probability of participants equals the survival probability of non-participants. In contrast, basic courses show the worst performance. The survival rates of Swiss men who participate in a basic course are always above the survival rates of comparable non-participants because basic courses do not have a positive effect on the job hazard. Employment programs, language courses and other courses display break even durations which are longer than two years - the maximum benefit entitlement period in Switzerland. Clearly, negative effects during participation and more importantly low effects after participation are responsible for long break even durations for Swiss males.

The situation is different for Swiss females. All except one break-even duration are shorter than 6 months. Employment programs have the lowest

unemployed individual will have to attend an ALMP when benefits expire. 
possible break even duration of zero months because participants never have lower exit rates than comparable non-participants. Unambiguously, employment programs shorten unemployment duration for Swiss females. While computer courses, basic courses and other courses do impede job-search during the program, they are short (basic courses and computer courses) or exhibit strong positive effects after participation (other courses). For these reasons, computer courses, basic courses and other courses exhibit relatively short break even durations of 1.5, 2.5 and 5.7 months. Language courses have the worst break even duration for females; it takes more than 2 years until the cumulative exit probability of participants is the same as that of non-participants.

In summary, we find that programs increase unemployment duration for Swiss males, but tend to shorten unemployment duration for Swiss females. It takes quantitatively strong positive effects on the job hazard after participation to make up for the strong reduction in the exit rate from unemployment during the program.

\section{Conclusions}

The Swiss labor market policy enacted in 1997 created a link between entitlement to unemployment benefits and participation in active labor market programs (ALMPs). This paper evaluates the effect of participating in ALMPs as well as the effect of a change in benefit eligibility status on the duration of unemployment in Switzerland. Our evaluation methodology takes possible selectivity in the inflow into programs into account.

Our main result shows that there is an important trade-off between training the unemployed and reducing unemployment duration. Most active labor market programs have positive - albeit sometimes not significant - effects on the transition rate to jobs after the program ends. However, almost all participants experience a significant reduction in the job-hazard rate during the program. Simulations show that it takes quantitatively high effects after program to compensate for the negative effects during participation if programs are asked to deliver positive effects as early as 9 months after the program starts.

Second, we show that linking unemployment benefits to participation in a program increases transitions to a regular job shortly before and permanently after participation has become a requirement for further benefit-entitlement. It appears that assignment to training is interpreted like a punishment by some job-seekers.

We draw two conclusions for active labor market policy: (i) Training and 
employment programs must be structured such that there is enough time for continuous job search. (ii) Linking participation in ALMPs tightly to unemployment benefits can reduce unemployment duration considerably.

Our analysis does not shed light on the effects of ALMPs on other outcome variables. The duration of the first job after an ALMP would be a good indicator of the medium-run effects of a program. The wage in the first job after an ALMP would measure more directly by how much general skills of the unemployed improved through the program. While our data do not allow us to study these questions, further research should address these important issues. 


\section{References}

- Abbring, Jaap H., Van den Berg, Gerard J., and Van Ours, Jan C.(1997), The Effect of Unemployment Insurance Sanctions on the Transition Rate from Unemployment to Employment, mimeo, Tinbergen Institute, Amsterdam/Rotterdam.

- Abbring, Jaap H, and Van den Berg, Gerard J. (1998), The NonParametric Identification of Treatment Effects in Duration Models, mimeo, Vrije Universiteit Amsterdam.

- Akaike, Hirotugu (1973), Information Theory and Extension of the Maximum Likelihood Principle, in B.N. Petrov and C.Csaki (eds.), Second International Symposium on Information Theory, Akademiai Kiado, Budapest, 267-281.

- Black, Dan A., Berger, Mark C., Noel, Brett J., and Smith, Jeffrey A. (1998), Is the Threat of Training More Effective than Training Itself? Experimental Evidence from UI Claimant Profiling, mimeo, University of Kentucky.

- Bonnal, Liliane, Fougère, Denis, Sérandon, Anne (1997), Evaluating the Impact of French Employment Policies on Individual Labour Market Histories, Review of Economic Studies, 683-713.

- Curti, Monica (1998), Evaluating Active Labour Market Policy - The Swiss Experience, Swiss Office of Economic Development and Labour, Berne.

- Gerfin, Michael, and Schellhorn, Martin (1995), Duration Dependence of the Exit from Unemployment, in Steiner, Viktor, and Bellmann, Lutz (1995), Microeconomic Studies of the Labour Market, Beiträge zur Arbeitsmarkt- und Berufsforschung, Nürnberg.

- Gerfin, Michael and Michael Lechner (2000), Microeconometric Evaluation of Active Labour Market Policies in Switzerland, mimeo, University of St. Gallen.

- Gritz, Mark (1993), The Impact of Training on the Frequency and Duration of Employment, Journal of Econometrics, 57, 21-51.

- Heckman, James J., and Singer, Burton (1984), A Method for Minimizing the Impact of Distributional Assumptions in Econometric Models for Duration Data, Econometrica, 52, 271-320. 
- Heckman, James J., Ichimura, Hidehiko and Petra E. Todd (1997), Matching as an Econometric Evaluation Estimator: Evidence from Evaluating a Job Training Programme, Review of Economic Studies, vol. 64, 605-654.

- Heckman, James J., LaLonde, Robert J., and Smith, Jeffrey A. (1999), The Economics and Econometrics of Active Labor Market Programs, in: Ashenfelter, Orley, and Card, David (eds.) Handbook of Labor Economics, volume III, North-Holland.

- Hübler, Olaf (1997), An Evaluation of Employment Measures in East Germany, Jahrbücher für Nationalökonomie und Statistik, 216, 21-44.

- Lubyova, Martina, and Van Ours, Jan C. (1999), Effects of Active Labour Market programs on the Transition Rate from Unemployment into Regular Jobs in the Slovak Republic, Journal of Comparative Economics, 27, 90-112.

- OECD (1996), Labor Market Policies in Switzerland, Paris.

- Sheldon, George (1999), Die Langzeitarbeitslosigkeit in der Schweiz, Diagnose und Therapie, Haupt Publishers, Berne.

- Van den Berg, Gerard J., Van der Klaauw, Bas, and Van Ours, Jan C. (1998), Punitive Sanctions and the Transition Rate from Welfare to Work, Discussion Paper, No. 9856, CentER for Economic Research, Tilburg University.

- Van den Berg, Gerard J., Holm, Anders, and Van Ours, Jan C. (1999), Does Work Experience Help to Become a Medical Specialist?, Discussion Paper, No. 9919, CentER for Economic Research, Tilburg University.

- Van den Berg, Gerard J. (2000), Duration Models: Specification, Identification, and Multiple Durations, in: Heckman, James J., and Leamer, Edward (eds.) Handbook of Econometrics, Volume V, North-Holland, forthcoming.

- Van Ours, Jan C. (2000), Do Active Labour Market Policies Help Unemployed Workers to Find and Keep Regular Jobs?, Discussion Paper, No. 0010, CentER for Economic Research, Tilburg University. 
Table 1

Descriptive statistics for a subset of covariates, Swiss Males and Swiss Females

\begin{tabular}{lcccc}
\hline \hline & All & $\begin{array}{c}\text { Non } \\
\text { Participants }\end{array}$ & $\begin{array}{c}\text { Participants in } \\
\text { Training } \\
\text { Courses }\end{array}$ & $\begin{array}{c}\text { Participants in } \\
\text { Employment } \\
\text { Programs }\end{array}$ \\
\hline & & & & \\
Age & & & & \\
16 to 30 & 0.43 & 0.46 & 0.32 & 0.37 \\
30 to 50 & 0.44 & 0.42 & 0.53 & 0.48 \\
50 to 65 & 0.13 & 0.12 & 0.15 & 0.15 \\
Skill Level & & & & \\
Unskilled & 0.08 & 0.08 & 0.06 & 0.14 \\
Medium & 0.10 & 0.10 & 0.08 & 0.12 \\
High & 0.82 & 0.82 & 0.86 & 0.74 \\
Employability ${ }^{\text {b) }}$ & & & & \\
Bad & 0.11 & 0.10 & 0.11 & 0.19 \\
Medium & 0.53 & 0.53 & 0.52 & 0.58 \\
Good & 0.25 & 0.25 & 0.28 & 0.18 \\
$\quad$ Unknown & 0.11 & 0.12 & 0.09 & 0.05 \\
Wage in previous Job ${ }^{\text {c) }}$ & 4.14 & 4.08 & 4.59 & 3.69 \\
Number of Observations & & & & $\mathbf{3 7 0}$ \\
\hline
\end{tabular}

Age

$\begin{array}{lllll}16 \text { to } 30 & 0.48 & 0.51 & 0.38 & 0.52 \\ 30 \text { to } 50 & 0.42 & 0.40 & 0.51 & 0.37 \\ 50 \text { to } 65 & 0.10 & 0.09 & 0.11 & 0.11 \\ \text { Skill Level } & & & & \\ \text { Unskilled } & 0.15 & 0.16 & 0.14 & 0.18 \\ \text { Medium } & 0.11 & 0.10 & 0.12 & 0.13 \\ \text { High } & 0.74 & 0.74 & 0.74 & 0.69\end{array}$

Employability ${ }^{\text {b) }}$

$\mathrm{Bad}$

$\begin{array}{llll}0.09 & 0.10 & 0.07 & 0.08\end{array}$

Medium

$0.58 \quad 0.57$

$0.60 \quad 0.63$

Good

0.25

0.25

0.25

0.24

Unknown

0.08

0.08

0.05

Wage in previous $\mathrm{Job}^{\mathrm{c})}$

3.45

3.39

3.74

3.18

Number of Observations

3686

2754

737

195

Notes: a) See notes of Table 2 for a description of training courses.

b) Subjective rating by public employment service staff at beginning of unemployment spell.

c) In SFR (1 SFR was approx. 0.75 USD in 1997), divided by 1000. 
Table 2

Descriptive Statistics of Active Labor Market Programs ${ }^{\text {a) }}$

\begin{tabular}{|c|c|c|c|c|c|}
\hline & \# Obs. & [\%] & $\begin{array}{c}\text { Elapsed } \\
\text { ALMP-Duration } \\
{[\text { Months ] }}\end{array}$ & $\begin{array}{c}\text { Completed } \\
\text { ALMP-Spells } \\
{[\%]}\end{array}$ & $\begin{array}{c}\text { Unemployment } \\
\text { Duration at Entry } \\
\text { [ Months ] }\end{array}$ \\
\hline & \multicolumn{4}{|c|}{ SWISS MALES } & \\
\hline \multicolumn{6}{|l|}{ Training Courses } \\
\hline Basic Course $^{\mathrm{b})}$ & 523 & 35.7 & 0.6 & 92.4 & 2.7 \\
\hline Language Course $^{\mathrm{c})}$ & 87 & 5.9 & 2.0 & 79.3 & 3.5 \\
\hline Computer Course $^{\mathrm{d})}$ & 238 & 16.2 & 0.9 & 89.1 & 3.3 \\
\hline Other Course $^{\mathrm{e})}$ & 248 & 16.9 & 1.7 & 80.2 & 3.6 \\
\hline Employment Programme ${ }^{\mathrm{f}}$ & 370 & 25.2 & 4.7 & 62.4 & 4.4 \\
\hline Total & 1466 & 100.0 & 2.0 & 81.4 & 3.4 \\
\hline & \multicolumn{4}{|c|}{ SWISS FEMALES } & \\
\hline \multicolumn{6}{|l|}{ Training Courses } \\
\hline Basic Course ${ }^{b)}$ & 320 & 34.3 & 0.7 & 88.1 & 3.1 \\
\hline Language Course ${ }^{c)}$ & 110 & 11.8 & 2.1 & 72.7 & 3.4 \\
\hline Computer Course $^{\mathrm{d})}$ & 212 & 22.7 & 0.7 & 91.5 & 3.3 \\
\hline Other Course ${ }^{\mathrm{e})}$ & 95 & 10.2 & 2.5 & 75.8 & 3.4 \\
\hline Employment Programme ${ }^{\mathrm{f}}$ & 195 & 20.9 & 4.5 & 57.9 & 3.9 \\
\hline Total & 932 & 100 & 1.9 & 79.5 & 3.4 \\
\hline
\end{tabular}

Notes : a) First ALMP which lasted longer than one week.

b) Courses aiming at improving the effectiveness of individual job search and self-esteem.

c) Language courses (reading and writing skills).

d) Basic word processing and spreadsheet calculation.

e) Specific computer training, business administration, technical training, courses in the tourism and the health sector, ...

f) Temporary jobs in the Non-Profit sector (government, NGOs, ...). 
Table 3

The effect of ALMPs and Benefit Exhaustion on transitions to a regular job

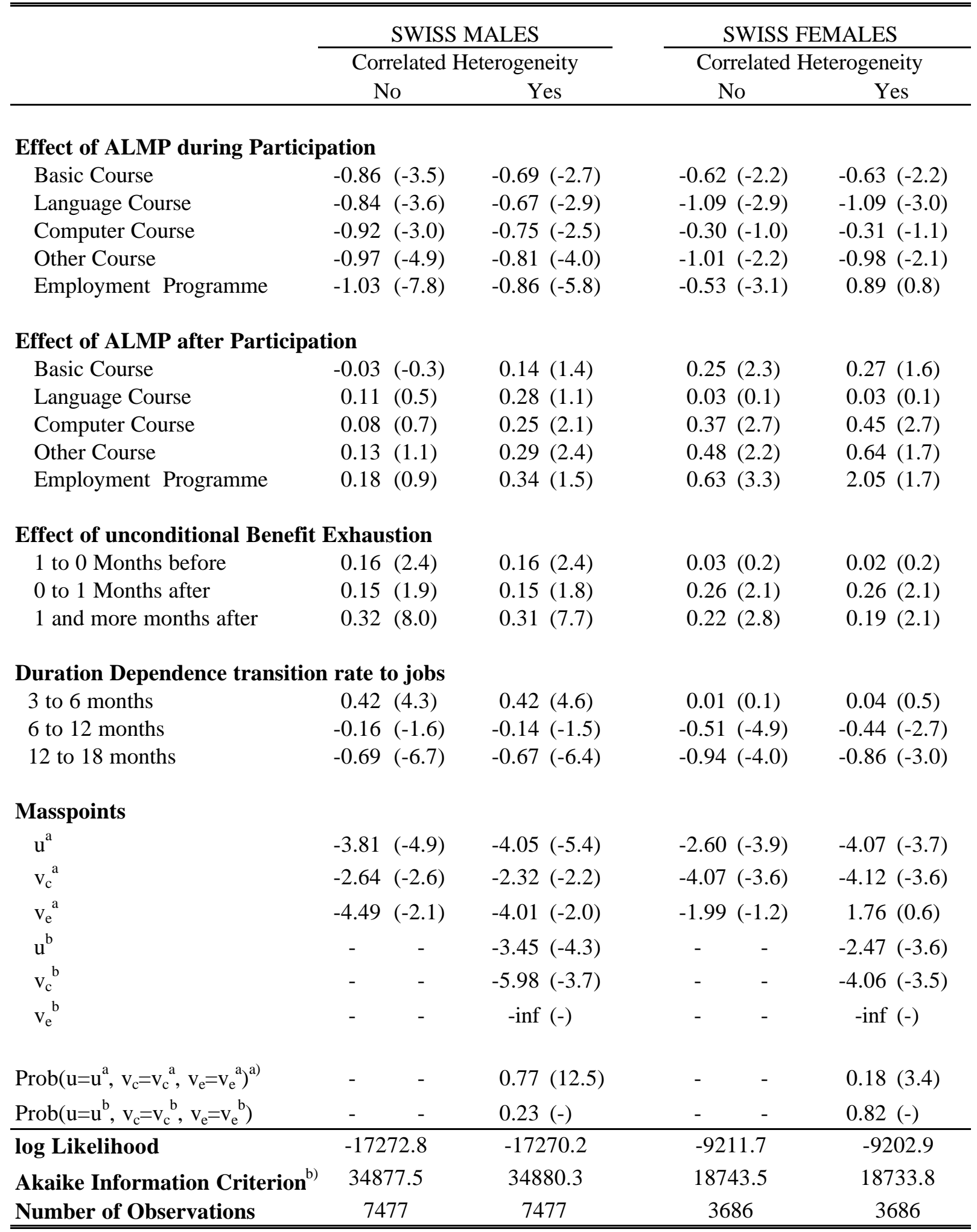

Notes: t-Values in parentheses. All estimates control for family situation, age, skill level, employability, inflow period, industry, occupation, urbanization, cantonal unemployment rate, cantonal ALMP-participation rate and percentage in favor of cutting benefits, information on previous employment spell, recent (1988-1995) and distant (1995-1997) employment history.

a) The correlated model allows for 4-point heterogeneity. Estimation reveals that two points suffice.

b) The preferred model minimizes the Akaike Information Criterion 
Table 4

The impact of Benefit Entitlement on ALMP-entry rates

\section{SWISS MALES SWISS FEMALES}

\begin{tabular}{llr}
\hline Entry into Training Courses & & \\
1 to 0 Months before Exhaustion. & $0.15(0.76)$ & $-0.07(-0.35)$ \\
0 to 1 Months after Exhaustion. & $0.37(2.12)$ & $0.62(4.08)$ \\
1 and more months after Exhaustion. & $0.39(3.75)$ & $0.26(2.34)$ \\
& & \\
& & \\
Entry into Employment Programmes & $0.34(0.96)$ & $0.53(1.88)$ \\
1 to 0 Months before Exhaustion. & $0.78(4.03)$ & $0.60(2.22)$ \\
0 to 1 Months after Exhaustion. & $0.59(3.26)$ & $1.46(4.33)$ \\
1 and more months after Exhaustion. & 7477 & 3686 \\
\hline Number of Observations
\end{tabular}

Notes: Results are based on the model in Table 3 column 1 (Swiss males), and the model in Table 3 column 4 (Swiss females). 
Table 5

Effect of Second ALMP ${ }^{\text {a) }}$ and Duration Dependence in the effect after participation

\begin{tabular}{|c|c|c|}
\hline & SWISS MALES & SWISS FEMALES \\
\hline \multicolumn{3}{|c|}{ Effect of SECOND ALMP during Participation } \\
\hline Basic Course & $-1.22(-1.95)$ & $-0.38(-0.66)$ \\
\hline Language Course & NA NA & $-1.57(-1.67)$ \\
\hline Computer Course & $-2.38(-2.34)$ & $-0.99(-1.11)$ \\
\hline Other Course & $-1.07(-2.90)$ & $-0.32(-0.68)$ \\
\hline Employment Programme & $-1.02(-3.81)$ & $-0.39(-1.46)$ \\
\hline \multicolumn{3}{|c|}{ Effect of SECOND ALMP after Participation } \\
\hline Basic Course & $-0.60(-1.47)$ & $0.35(0.92)$ \\
\hline Language Course & $0.25(0.35)$ & $0.46(1.06)$ \\
\hline Computer Course & $-0.02(-0.06)$ & $0.73(3.98)$ \\
\hline Other Course & $0.49(2.62)$ & $0.20(0.37)$ \\
\hline Employment Programme & $0.46(1.86)$ & $0.76(1.82)$ \\
\hline \multicolumn{3}{|c|}{ Effect of ALMP 0 TO 2 MONTHS after Participation } \\
\hline Basic Course & $-0.01(-0.07)$ & $0.31(1.98)$ \\
\hline Language Course & $0.33(1.56)$ & $-0.25(-0.62)$ \\
\hline Computer Course & $0.05(0.39)$ & $0.50(3.00)$ \\
\hline Other Course & $0.18(0.89)$ & $0.59(1.45)$ \\
\hline Employment Programme & $0.28(1.12)$ & $2.43(1.66)$ \\
\hline \multicolumn{3}{|c|}{ Effect of ALMP MORE THAN 2 MONTHS after Participation } \\
\hline Basic Course & $-0.06(-0.51)$ & $0.36(1.30)$ \\
\hline Language Course & $-0.20(-0.54)$ & $0.47(1.81)$ \\
\hline Computer Course & $0.12(0.58)$ & $0.55(1.59)$ \\
\hline Other Course & $0.05(0.32)$ & $1.08(1.15)$ \\
\hline Employment Programme & $-0.01(-0.04)$ & $2.19(1.41)$ \\
\hline Number of Observations & 7477 & 3686 \\
\hline
\end{tabular}

Notes : a) Effect of Second ALMP measured with respect to nonparticipants. 
Table 6

The Break Even Duration ${ }^{\text {a) }}$ of Active Labor Market Programs

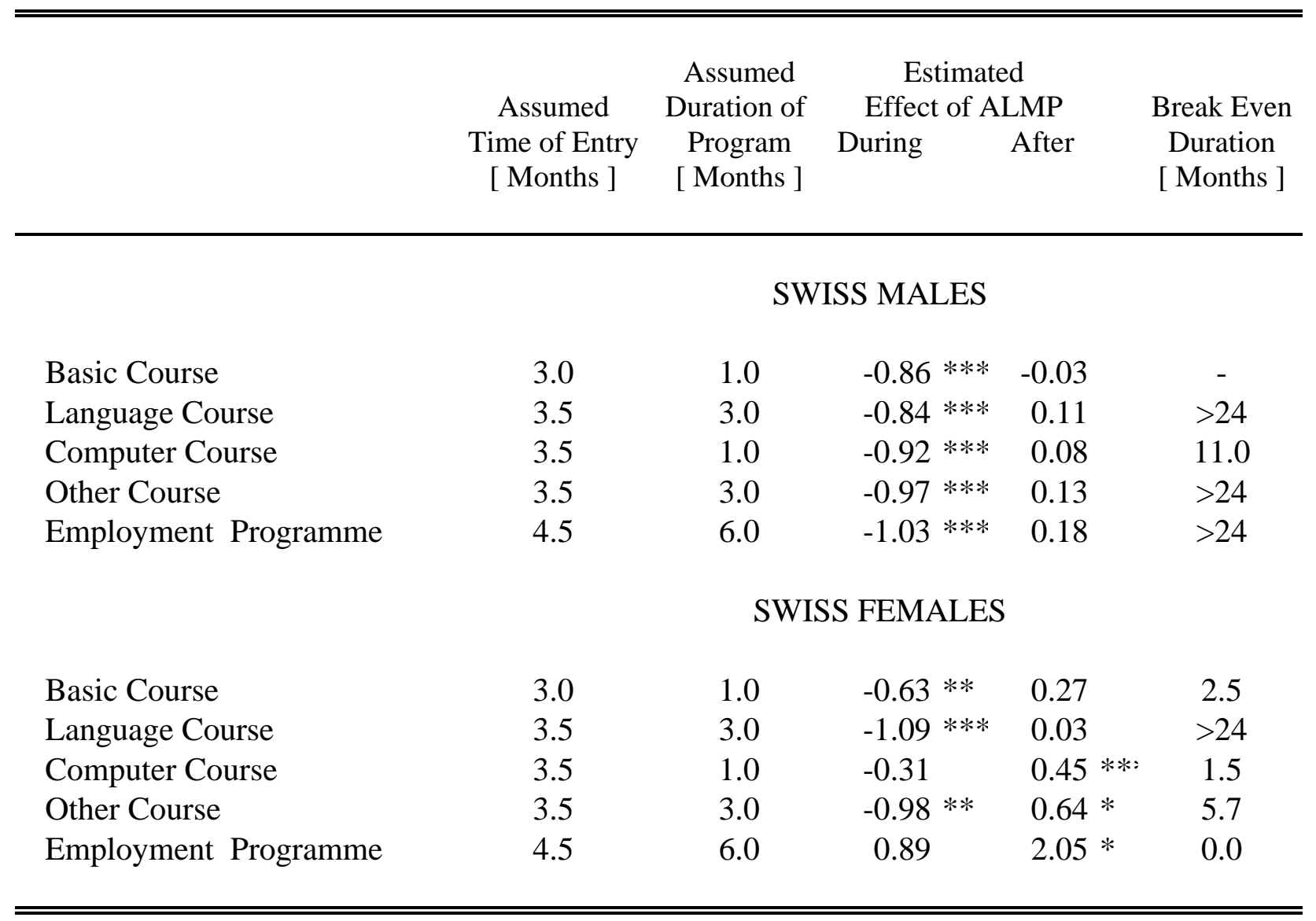

Notes: a) The break even duration is the time from ALMP start until ALMP participants have the same cumulative survival probability as non-participants.

Results are based on the model in Table 3 column 1 (Swiss males), and the model in Table 3 column 4 (Swiss females). ***,**.* denotes $1 \%, 5 \%$, and $10 \%$ level of significance. 


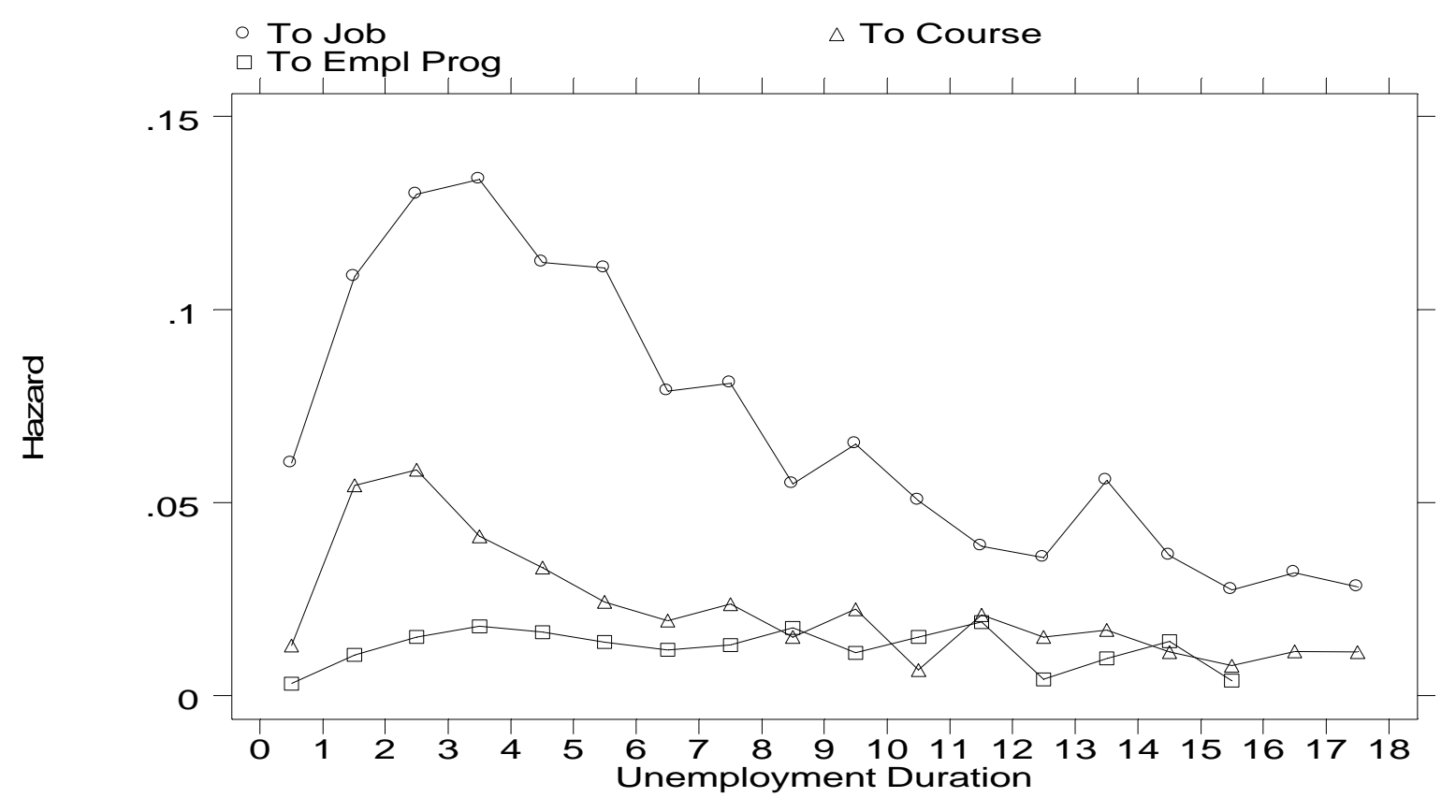

Figure 1a. Empirical transition rates, Swiss Males.

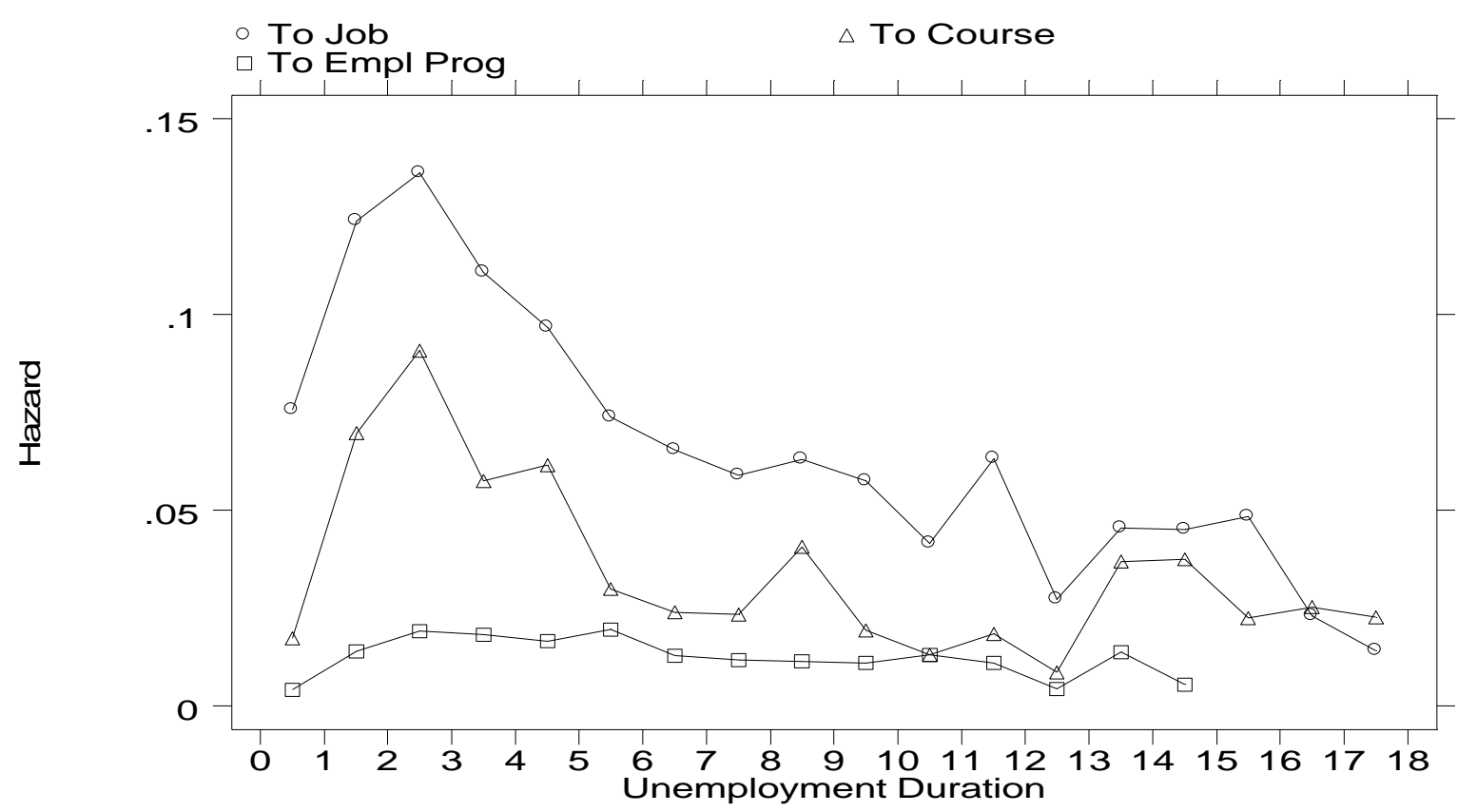

Figure 1b. Empirical transition rates, Swiss Females. 


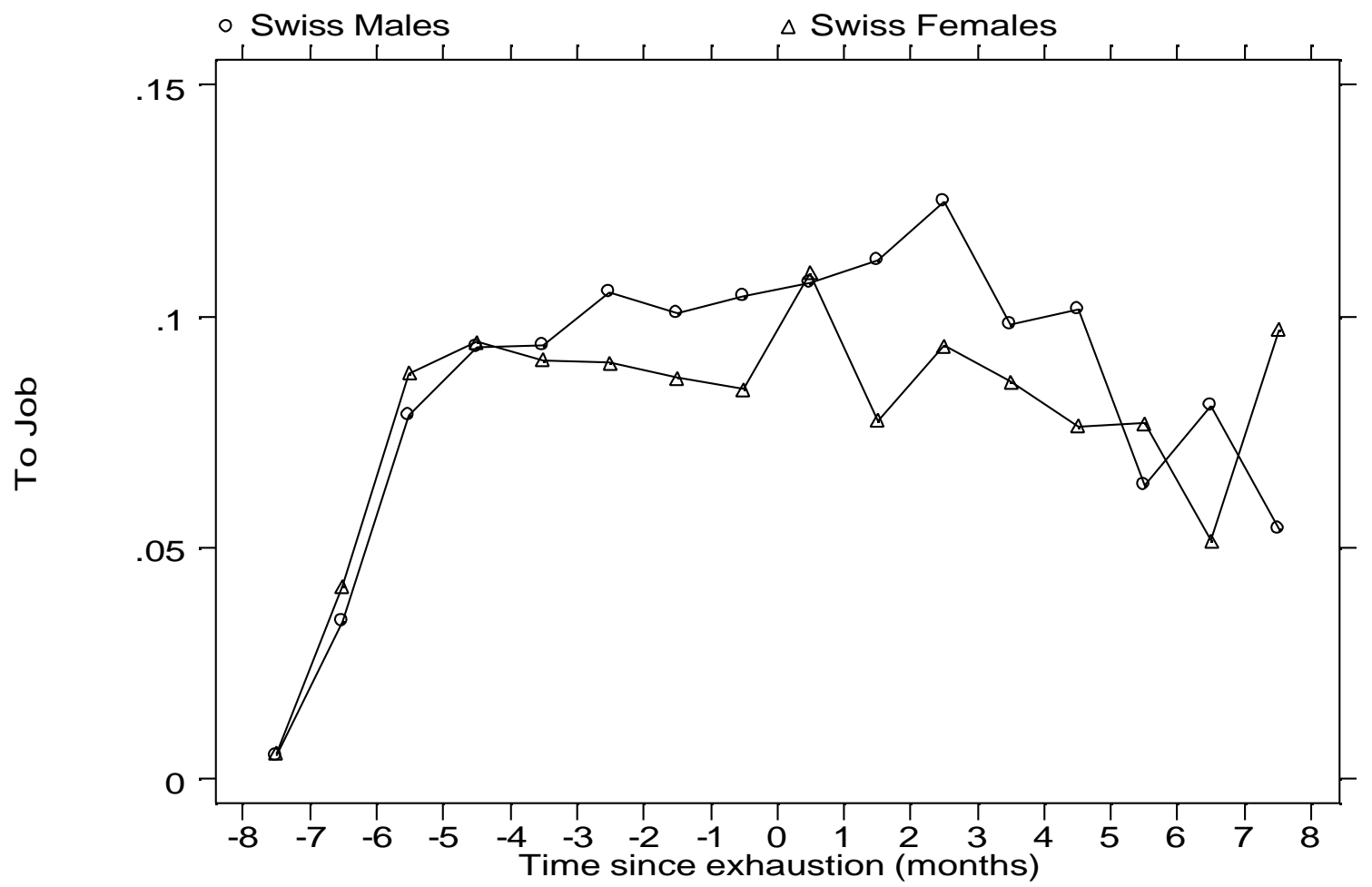

Figure 2. Transition rate to jobs by time since exhaustion of unconditional benefit eligibility (negative (positive) number is before (after) Exhaustion) 


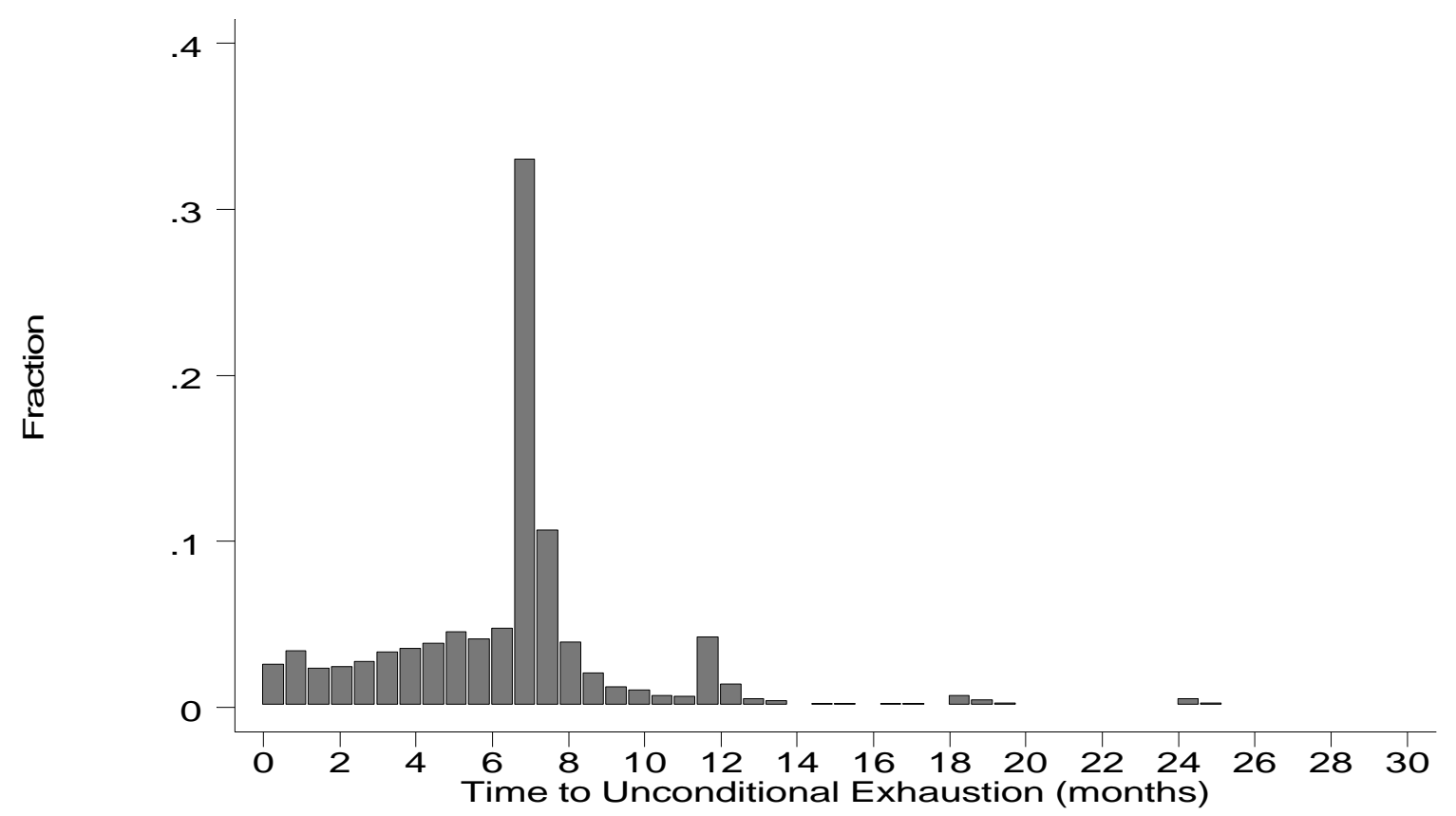

Figure 3a. Unconditional benefit eligibility duration, Swiss Males.

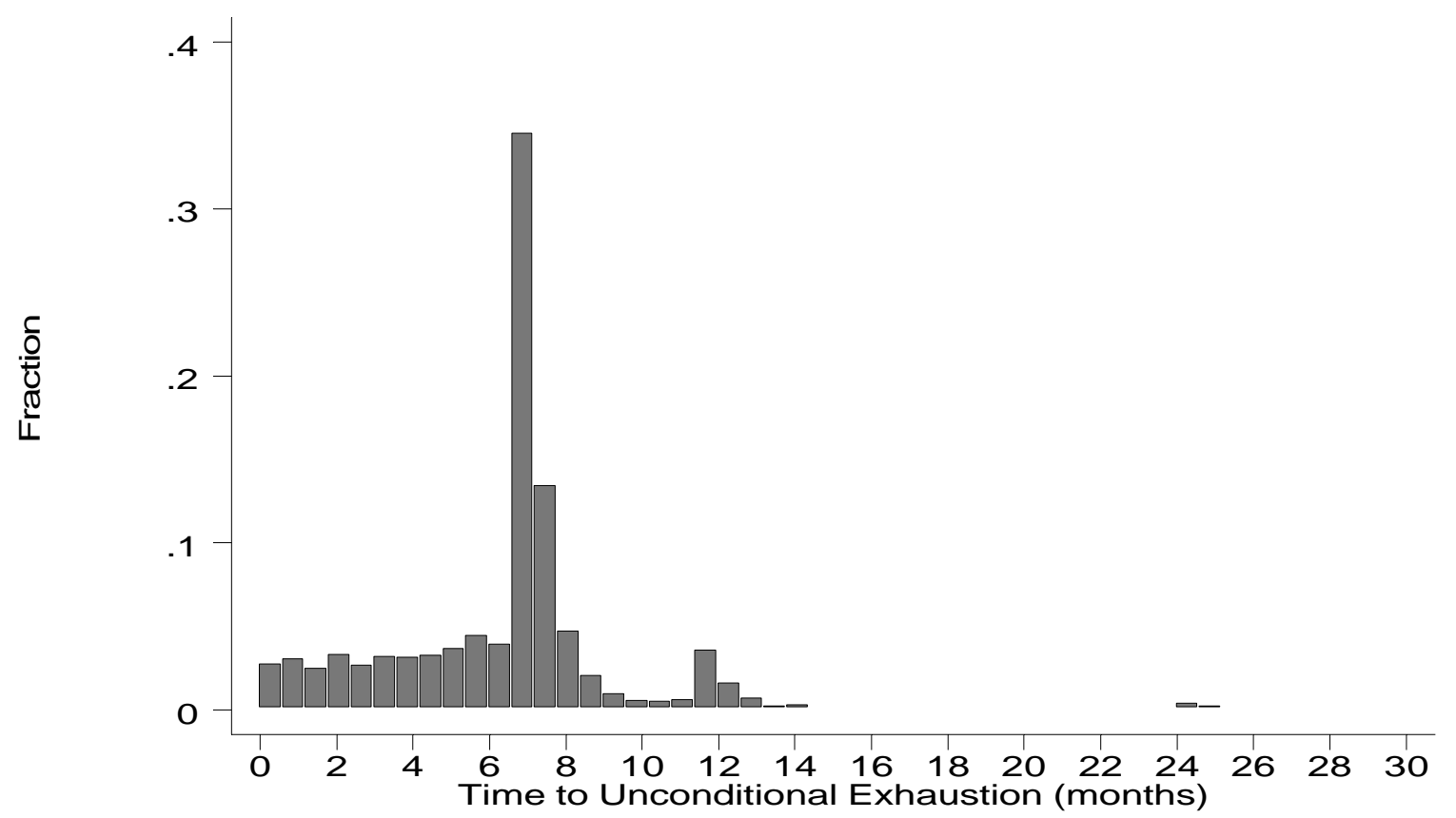

Figure $3 b$. Unconditional benefit eligibility duration, Swiss Females. 
Supplementary information for the referee

The Impact of Active Labor Market Programs and Benefit Entitlement Rules on the Duration of Unemployment

March 6, 2000 


\begin{tabular}{|c|c|c|c|c|}
\hline & ALL & $\begin{array}{c}\text { Non } \\
\text { Participants }\end{array}$ & $\begin{array}{l}\text { Participants in } \\
\text { Training } \\
\text { Courses }\end{array}$ & $\begin{array}{l}\text { Participants in } \\
\text { Employment } \\
\text { Programmes }\end{array}$ \\
\hline \multicolumn{5}{|l|}{ Unemployment Spell } \\
\hline Elapsed Duration & 4.72 & 4.00 & 6.63 & 10.73 \\
\hline Exit to Job & 0.48 & 0.51 & 0.33 & 0.31 \\
\hline Unconditional Benefit Eligibility at Start $^{\mathrm{a}}$ & 6.73 & 6.64 & 7.03 & 6.94 \\
\hline \multicolumn{5}{|l|}{ Individual Characteristics } \\
\hline Married & 0.31 & 0.30 & 0.36 & 0.26 \\
\hline Number of Dep. & 0.67 & 0.65 & 0.86 & 0.60 \\
\hline \multicolumn{5}{|l|}{ Age } \\
\hline 16 to 30 & 0.43 & 0.46 & 0.32 & 0.37 \\
\hline 30 to 50 & 0.44 & 0.42 & 0.53 & 0.48 \\
\hline 50 to 65 & 0.13 & 0.12 & 0.15 & 0.15 \\
\hline \multicolumn{5}{|l|}{ Skill Level } \\
\hline Unskilled & 0.08 & 0.08 & 0.06 & 0.14 \\
\hline Medium & 0.10 & 0.10 & 0.08 & 0.12 \\
\hline High & 0.82 & 0.82 & 0.86 & 0.74 \\
\hline \multicolumn{5}{|l|}{ Employability } \\
\hline Bad & 0.11 & 0.10 & 0.11 & 0.19 \\
\hline Medium & 0.53 & 0.53 & 0.52 & 0.58 \\
\hline Good & 0.25 & 0.25 & 0.28 & 0.18 \\
\hline Unknown & 0.11 & 0.12 & 0.09 & 0.05 \\
\hline Looking for Other Occupation & 0.27 & 0.26 & 0.31 & 0.36 \\
\hline \multicolumn{5}{|l|}{ Other Characteristics } \\
\hline \multicolumn{5}{|l|}{ Inflow Period } \\
\hline Dec 97 & 0.44 & 0.44 & 0.48 & 0.40 \\
\hline Jan 98 & 0.28 & 0.28 & 0.26 & 0.29 \\
\hline Feb 98 & 0.16 & 0.16 & 0.14 & 0.14 \\
\hline March 98 & 0.12 & 0.12 & 0.12 & 0.17 \\
\hline \multicolumn{5}{|l|}{ Industry } \\
\hline Construction & 0.23 & 0.25 & 0.17 & 0.17 \\
\hline Tourism & 0.06 & 0.06 & 0.06 & 0.05 \\
\hline Manufacturing & 0.19 & 0.18 & 0.20 & 0.17 \\
\hline Transport / Utilities & 0.07 & 0.07 & 0.06 & 0.06 \\
\hline Wholesale and Retail Trade & 0.14 & 0.13 & 0.18 & 0.15 \\
\hline Financial Services & 0.03 & 0.02 & 0.04 & 0.02 \\
\hline Other Services & 0.25 & 0.26 & 0.27 & 0.33 \\
\hline Entry from Nonemployment & 0.03 & 0.03 & 0.02 & 0.05 \\
\hline \multicolumn{5}{|l|}{ Occupation } \\
\hline Construction & 0.16 & 0.17 & 0.09 & 0.16 \\
\hline Tourism & 0.06 & 0.06 & 0.05 & 0.06 \\
\hline Other Occupations & 0.78 & 0.77 & 0.86 & 0.78 \\
\hline \multicolumn{5}{|l|}{ Urbanization } \\
\hline Village & 0.60 & 0.61 & 0.55 & 0.55 \\
\hline Small City & 0.14 & 0.14 & 0.14 & 0.17 \\
\hline Large City & 0.26 & 0.25 & 0.31 & 0.28 \\
\hline Log (Unemployment Rate in Canton) & 1.59 & 1.59 & 1.54 & 1.62 \\
\hline Log (ALMP-Participation Rate in Canton) & -1.52 & -1.53 & -1.47 & -1.49 \\
\hline Log (Percentage Votes for Benefit Cut in Canton) & 3.80 & 3.80 & 3.82 & 3.77 \\
\hline
\end{tabular}


Table A1a. (Continued)

\begin{tabular}{|c|c|c|c|c|}
\hline \multicolumn{5}{|l|}{$\begin{array}{l}\text { Earnings and Employment History } \\
\text { Previous Employment Spell }\end{array}$} \\
\hline No Previous Job & 0.01 & 0.02 & 0.00 & 0.01 \\
\hline Wage $^{b}$ & 4.14 & 4.08 & 4.59 & 3.69 \\
\hline Wage Squared & 19.64 & 19.10 & 23.91 & 15.77 \\
\hline Duration of previous Employment Spell ${ }^{d}$ & 2.80 & 2.74 & 3.31 & 2.21 \\
\hline \multicolumn{5}{|l|}{ Recent Past: 1995 to 1997} \\
\hline No Job & 0.01 & 0.01 & 0.01 & 0.01 \\
\hline Mean Wage ${ }^{\mathrm{b}}$ & 3.64 & 3.58 & 4.11 & 3.15 \\
\hline Variance of Wages $^{c}$ & 0.03 & 0.03 & 0.03 & 0.04 \\
\hline Percentage Employed & 0.80 & 0.80 & 0.81 & 0.75 \\
\hline Number of Employment Spells & 1.92 & 1.94 & 1.75 & 2.07 \\
\hline Percentage Unemployed & 0.10 & 0.10 & 0.09 & 0.12 \\
\hline Number of Unemployment Spells & 0.95 & 0.96 & 0.86 & 1.10 \\
\hline \multicolumn{5}{|l|}{ Distant Past: 1988 to 1994} \\
\hline No Job & 0.06 & 0.06 & 0.04 & 0.08 \\
\hline Mean Wageb & 2.93 & 2.87 & 3.41 & 2.58 \\
\hline Individual Wage Variance ${ }^{c}$ & 0.04 & 0.04 & 0.04 & 0.04 \\
\hline Percentage Employed & 0.82 & 0.83 & 0.84 & 0.77 \\
\hline Number of Employment Spells & 2.34 & 2.35 & 2.24 & 2.48 \\
\hline Percentage Unemployed & 0.04 & 0.04 & 0.05 & 0.06 \\
\hline Number of Unemployment Spells & 0.74 & 0.72 & 0.77 & 0.85 \\
\hline Number of Observations & 7477 & 6011 & 1096 & 370 \\
\hline
\end{tabular}

Notes: a. In months, measured at start of unemployment spell.

b. In Swiss Francs (1 SFR = .75 US Dollars in 1997), divided by 1000.

c. divided by $1,000,000$.

d. Duration of previous employment spell in the period 1988-1997, in years. 


\begin{tabular}{|c|c|c|c|c|}
\hline & ALL & $\begin{array}{c}\text { Non } \\
\text { Participants }\end{array}$ & $\begin{array}{l}\text { Participants in } \\
\text { Training } \\
\text { Courses }\end{array}$ & $\begin{array}{l}\text { Participants in } \\
\text { Employment } \\
\text { Programmes }\end{array}$ \\
\hline \multicolumn{5}{|l|}{ Unemployment Spell } \\
\hline Elapsed Duration & 4.73 & 3.88 & 6.59 & 9.78 \\
\hline Exit to Job & 0.47 & 0.52 & 0.31 & 0.41 \\
\hline Unconditional Benefit Eligibility at Start $^{\mathrm{a}}$ & 6.48 & 6.40 & 6.74 & 6.37 \\
\hline \multicolumn{5}{|l|}{ Individual Characteristics } \\
\hline Married & 0.23 & 0.22 & 0.28 & 0.26 \\
\hline Number of Dep. & 0.45 & 0.41 & 0.58 & 0.49 \\
\hline \multicolumn{5}{|l|}{ Age } \\
\hline 16 to 30 & 0.48 & 0.51 & 0.38 & 0.52 \\
\hline 30 to 50 & 0.42 & 0.40 & 0.51 & 0.37 \\
\hline 50 to 65 & 0.10 & 0.09 & 0.11 & 0.11 \\
\hline \multicolumn{5}{|l|}{ Skill Level } \\
\hline Unskilled & 0.15 & 0.16 & 0.14 & 0.18 \\
\hline Medium & 0.11 & 0.10 & 0.12 & 0.13 \\
\hline High & 0.74 & 0.74 & 0.74 & 0.69 \\
\hline \multicolumn{5}{|l|}{ Employability } \\
\hline Bad & 0.09 & 0.10 & 0.07 & 0.08 \\
\hline Medium & 0.58 & 0.57 & 0.60 & 0.63 \\
\hline Good & 0.25 & 0.25 & 0.25 & 0.24 \\
\hline Unknown & 0.08 & 0.08 & 0.08 & 0.05 \\
\hline Looking for Other Occupation & 0.27 & 0.26 & 0.29 & 0.40 \\
\hline \multicolumn{5}{|l|}{ Other Characteristics } \\
\hline \multicolumn{5}{|l|}{ Inflow Period } \\
\hline Dec 97 & 0.38 & 0.39 & 0.41 & 0.37 \\
\hline Jan 98 & 0.28 & 0.27 & 0.27 & 0.30 \\
\hline Feb 98 & 0.18 & 0.18 & 0.17 & 0.20 \\
\hline March 98 & 0.16 & 0.16 & 0.15 & 0.13 \\
\hline \multicolumn{5}{|l|}{ Industry } \\
\hline Construction & 0.02 & 0.02 & 0.03 & 0.02 \\
\hline Tourism & 0.16 & 0.17 & 0.13 & 0.10 \\
\hline Manufacturing & 0.13 & 0.12 & 0.15 & 0.14 \\
\hline Transport / Utilities & 0.04 & 0.04 & 0.05 & 0.04 \\
\hline Wholesale and Retail Trade & 0.20 & 0.20 & 0.20 & 0.15 \\
\hline Financial Services & 0.05 & 0.05 & 0.07 & 0.03 \\
\hline Other Services & 0.34 & 0.34 & 0.32 & 0.45 \\
\hline Entry from Nonemployment & 0.06 & 0.06 & 0.05 & 0.07 \\
\hline \multicolumn{5}{|l|}{ Occupation } \\
\hline Construction & 0.00 & 0.00 & 0.00 & 0.00 \\
\hline Tourism & 0.18 & 0.19 & 0.15 & 0.17 \\
\hline Other Occupations & 0.82 & 0.81 & 0.85 & 0.83 \\
\hline \multicolumn{5}{|l|}{ Urbanization } \\
\hline Village & 0.53 & 0.53 & 0.49 & 0.53 \\
\hline Small City & 0.18 & 0.18 & 0.19 & 0.19 \\
\hline Large City & 0.29 & 0.29 & 0.32 & 0.28 \\
\hline Log (Unemployment Rate in Canton) & 1.60 & 1.60 & 1.62 & 1.63 \\
\hline Log (ALMP-Participation Rate in Canton) & -1.52 & -1.53 & -1.52 & -1.50 \\
\hline Log (Percentage Votes for Benefit Cut in Canton) & 3.79 & 3.80 & 3.78 & 3.73 \\
\hline
\end{tabular}


Table A1b. (Continued)

\begin{tabular}{|c|c|c|c|c|}
\hline \multicolumn{5}{|l|}{$\begin{array}{l}\text { Earnings and Employment History } \\
\text { Previous Employment Spell }\end{array}$} \\
\hline No Previous Job & 0.01 & 0.01 & 0.00 & 0.00 \\
\hline Wage $^{\mathrm{a}}$ & 3.45 & 3.39 & 3.74 & 3.18 \\
\hline Wage Squared & 13.94 & 13.48 & 16.29 & 11.55 \\
\hline Duration of previous Employment Spell ${ }^{d}$ & 2.54 & 2.45 & 2.91 & 2.43 \\
\hline \multicolumn{5}{|l|}{ Recent Past: 1995 to 1997} \\
\hline No Job & 0.02 & 0.02 & 0.02 & 0.03 \\
\hline Mean Wage ${ }^{a}$ & 2.99 & 2.96 & 3.25 & 2.47 \\
\hline Variance of Wages ${ }^{\mathrm{C}}$ & 0.03 & 0.03 & 0.03 & 0.02 \\
\hline Percentage Employed & 0.76 & 0.76 & 0.79 & 0.74 \\
\hline Number of Employment Spells & 1.81 & 1.84 & 1.70 & 1.87 \\
\hline Percentage Unemployed & 0.11 & 0.11 & 0.10 & 0.12 \\
\hline Number of Unemployment Spells & 0.92 & 0.94 & 0.84 & 1.02 \\
\hline \multicolumn{5}{|l|}{ Distant Past: 1988 to 1994} \\
\hline No Job & 0.10 & 0.10 & 0.08 & 0.11 \\
\hline Mean Wagea & 2.18 & 2.14 & 2.43 & 1.84 \\
\hline Individual Wage Variance ${ }^{c}$ & 0.03 & 0.03 & 0.03 & 0.03 \\
\hline Percentage Employed & 0.74 & 0.74 & 0.75 & 0.69 \\
\hline Number of Employment Spells & 2.32 & 2.32 & 2.34 & 2.29 \\
\hline Percentage Unemployed & 0.05 & 0.05 & 0.06 & 0.06 \\
\hline Number of Unemployment Spells & 0.68 & 0.66 & 0.71 & 0.81 \\
\hline Number of Observations & 3686 & 2754 & 737 & 195 \\
\hline
\end{tabular}

Notes: a. In months, measured at start of unemployment spell.

b. In Swiss Francs (1 SFR = .75 US Dollars in 1997), divided by 1000.

c. divided by $1,000,000$.

d. Duration of previous employment spell in the period 1988-1997, in years. 
TO JOB

TO COURSE TO EMPL. PROG

\begin{tabular}{|c|c|c|c|c|}
\hline \multicolumn{5}{|l|}{ Individual Characteristics } \\
\hline Married & $0.07(1.35)$ & $-0.17(-1.17)$ & -0.34 & $(-2.93)$ \\
\hline Number of Dep. & $0.02(0.60)$ & $0.13(3.05)$ & 0.11 & $(1.94)$ \\
\hline \multicolumn{5}{|l|}{ Age (16 to 30$)$} \\
\hline 30 to 50 & $-0.40(-8.82)$ & $0.09(0.98)$ & 0.46 & (3.62) \\
\hline 50 to 65 & $-0.84(-7.67)$ & $-0.18(-1.29)$ & 0.53 & (2.95) \\
\hline \multicolumn{5}{|l|}{ Skill Level (Unskilled) } \\
\hline Medium & $0.11(1.10)$ & $0.06(0.46)$ & -0.13 & $(-0.45)$ \\
\hline High & $0.33(3.67)$ & $0.33(2.88)$ & -0.12 & $(-0.85)$ \\
\hline \multicolumn{5}{|l|}{ Employability (Unknown) } \\
\hline Bad & $-0.51 \quad(-5.97)$ & $0.11(0.54)$ & 0.99 & $(5.17)$ \\
\hline Medium & $-0.10(-1.14)$ & $0.10(0.67)$ & 0.70 & $(5.14)$ \\
\hline Good & $0.07(1.12)$ & $0.35(1.93)$ & 0.56 & $(2.45)$ \\
\hline Looking for Other Occupation & $-0.08(-2.36)$ & $0.18(2.93)$ & 0.26 & $(1.56)$ \\
\hline \multicolumn{5}{|l|}{ Other Characteristics } \\
\hline \multicolumn{5}{|l|}{ Inflow Period (Dec 97) } \\
\hline Jan 98 & $0.07(1.41)$ & $-0.17(-2.70)$ & -0.09 & $(-0.63)$ \\
\hline Feb 98 & $0.07(1.52)$ & $-0.30(-2.02)$ & -0.60 & $(-2.45)$ \\
\hline March 98 & $0.06(1.00)$ & $-0.31(-1.69)$ & -0.18 & $(-0.78)$ \\
\hline \multicolumn{5}{|l|}{ Industry (Other Services) } \\
\hline Construction & $0.13(3.50)$ & $-0.17(-1.34)$ & -0.52 & $(-2.66)$ \\
\hline Tourism & $0.12(1.51)$ & $0.28(1.89)$ & -0.53 & $(-1.27)$ \\
\hline Manufacturing & $0.05(1.35)$ & $-0.08(-0.69)$ & -0.32 & $(-2.24)$ \\
\hline Transport / Utilities & $0.15(2.09)$ & $-0.24(-1.39)$ & -0.34 & $(-1.11)$ \\
\hline Wholesale and Retail Trade & $0.02(0.45)$ & $0.18(1.89)$ & -0.27 & $(-2.09)$ \\
\hline Financial Services & $0.03(0.30)$ & $0.16(0.75)$ & -0.85 & $(-2.00)$ \\
\hline Entry from Nonemployment & $0.08(0.54)$ & $-0.03(-0.12)$ & 0.03 & $(0.09)$ \\
\hline \multicolumn{5}{|l|}{ Occupation (All Other) } \\
\hline Construction & $-0.01 \quad(-0.32)$ & $-0.45(-3.19)$ & 0.17 & $(0.75)$ \\
\hline Tourism & $0.03(0.26)$ & $-0.04(-0.18)$ & 0.30 & $(0.77)$ \\
\hline \multicolumn{5}{|l|}{ Urbanization (Village) } \\
\hline Small City & $-0.19(-3.83)$ & $0.17(1.57)$ & -0.12 & $(-0.66)$ \\
\hline Large City & $-0.23(-2.04)$ & $0.03(0.29)$ & -0.10 & $(-0.46)$ \\
\hline Log (Unemployment Rate in Canton) & $-0.42(-2.70)$ & $-0.39(-1.26)$ & 0.53 & $(0.68)$ \\
\hline Log (ALMP-Participation Rate in Canton) & $-0.06(-0.58)$ & $0.73(1.98)$ & 0.91 & $(2.07)$ \\
\hline Log (Percentage Votes for Benefit Cut in Canton) & $0.21(1.69)$ & $0.13(0.50)$ & 0.17 & $(0.40)$ \\
\hline \multicolumn{5}{|l|}{ Earnings and Employment History } \\
\hline \multicolumn{5}{|l|}{ Previous Employment Spell } \\
\hline No Previous Job & $-0.19(-0.65)$ & $-2.09(-2.27)$ & -1.35 & $(-1.84)$ \\
\hline Wage & $0.24(3.74)$ & $0.20(2.25)$ & 0.05 & $(0.54)$ \\
\hline Wage Squared & $-0.03(-4.50)$ & $-0.01(-0.89)$ & -0.01 & $(-1.23)$ \\
\hline Duration of Last Employment Spell & $-0.02(-2.90)$ & $-0.01(-1.03)$ & -0.01 & $(-0.60)$ \\
\hline \multicolumn{5}{|l|}{ Recent Past: 1994 to 1997} \\
\hline No Job & $0.01(0.04)$ & $-0.37(-0.81)$ & -0.27 & $(-0.39)$ \\
\hline Mean Wage & $0.03(0.81)$ & $0.03(0.90)$ & 0.01 & $(0.18)$ \\
\hline Variance of Wages & $-0.24(-0.49)$ & $-0.15(-0.29)$ & 0.14 & $(0.13)$ \\
\hline Percentage Employed & $0.54(4.35)$ & $0.05(0.16)$ & 0.19 & $(0.84)$ \\
\hline Number of Employment Spells & $0.02(0.69)$ & $-0.13(-2.04)$ & 0.00 & $(0.04)$ \\
\hline Percentage Unemployed & $-0.83(-3.74)$ & $-1.56(-3.77)$ & -0.46 & $(-1.01)$ \\
\hline Number of Unemployment Spells & $0.05(1.80)$ & $0.07(1.49)$ & 0.04 & $(0.59)$ \\
\hline
\end{tabular}


Table A2a. (Continued)

\begin{tabular}{|c|c|c|c|c|}
\hline \multicolumn{5}{|l|}{ Distant Past: 1988 to 1994} \\
\hline No Job & $0.15(1.01)$ & $-0.13(-0.58)$ & -0.34 & $(-0.70)$ \\
\hline Mean Wage & $0.01(0.97)$ & $0.02(0.46)$ & -0.12 & $(-2.43)$ \\
\hline Individual Wage Variance & $0.72(2.66)$ & $0.14(0.28)$ & -0.14 & $(-0.18)$ \\
\hline Percentage Employed & $0.43(2.88)$ & $-0.20(-0.82)$ & -0.41 & $(-0.97)$ \\
\hline Number of Employment Spells & $-0.01(-0.69)$ & $-0.08(-2.12)$ & -0.08 & $(-1.74)$ \\
\hline Percentage Unemployed & $-1.71(-4.22)$ & $0.77(2.14)$ & 0.04 & $(0.06)$ \\
\hline Number of Unemployment Spells & $0.03(0.82)$ & $0.06(1.19)$ & 0.02 & $(0.41)$ \\
\hline \multicolumn{5}{|l|}{ Masspoints } \\
\hline$u^{a}, v_{c}^{a}, v_{e}^{a}$ & $-3.81(-4.91)$ & $-2.64(-2.64)$ & -4.49 & $(-2.14)$ \\
\hline \multicolumn{5}{|l|}{ Duration Dependence (0 to 3 Months) } \\
\hline 3 to 6 Months & $0.42(4.35)$ & $-0.01(-0.05)$ & 0.55 & $(2.60)$ \\
\hline 6 to 12 Months & $-0.16(-1.64)$ & $-0.69(-4.28)$ & 0.15 & $(0.89)$ \\
\hline 12 to 18 Months & $-0.69(-6.72)$ & $-0.99(-3.58)$ & -0.59 & $(-2.20)$ \\
\hline \multicolumn{5}{|c|}{ Effect of unconditional Benefit Exhaustion } \\
\hline 1 to 0 Months before Exhaustion & $0.16(2.42)$ & $0.15(0.76)$ & 0.34 & $(0.96)$ \\
\hline 0 to 1 Months after Exhaustion & $0.15(1.86)$ & $0.37(2.12)$ & 0.78 & $(4.03)$ \\
\hline 1 and more Months after Exhaustion & $0.32(8.01)$ & $0.39(3.75)$ & 0.59 & (3.26) \\
\hline \multicolumn{5}{|l|}{ Effect of ALMP during Participation } \\
\hline Basic Course & $-0.86(-3.50)$ & & & \\
\hline Language Course & $-0.84(-3.63)$ & & & \\
\hline Computer Course & $-0.92(-3.00)$ & & & \\
\hline Other Course & $-0.97(-4.91)$ & & & \\
\hline Employment Programme & $-1.03(-7.78)$ & & & \\
\hline \multicolumn{5}{|l|}{ Effect of ALMP after Participation } \\
\hline Basic Course & $-0.03(-0.30)$ & & & \\
\hline Language Course & $0.11(0.51)$ & & & \\
\hline Computer Course & $0.08(0.73)$ & & & \\
\hline Other Course & $0.13(1.09)$ & & & \\
\hline Employment Programme & $0.18(0.86)$ & & & \\
\hline log Likelihood & -17272.8 & & & \\
\hline Number of Observations & 7477 & & & \\
\hline
\end{tabular}

Note: t-Values in parentheses. 
Table A2b. The effect of ALMPs and Benefit Exhaustion, Males, with correlated Heterogeneity

TO JOB

TO COURSE TO EMPL. PROG

\begin{tabular}{|c|c|c|c|c|}
\hline \multicolumn{5}{|l|}{ Individual Characteristics } \\
\hline Married & $0.09(1.54)$ & $-0.19(-1.30)$ & -0.39 & $(-3.04)$ \\
\hline Number of Dep. & $0.01(0.43)$ & $0.14(3.14)$ & 0.13 & $(2.13)$ \\
\hline \multicolumn{5}{|l|}{ Age (16 to 30$)$} \\
\hline 30 to 50 & $-0.42(-8.91)$ & $0.12(1.24)$ & 0.50 & (3.93) \\
\hline 50 to 65 & $-0.86(-7.30)$ & $-0.16(-1.12)$ & 0.59 & (3.22) \\
\hline \multicolumn{5}{|l|}{ Skill Level (Unskilled) } \\
\hline Medium & $0.11(1.10)$ & $0.07(0.47)$ & -0.13 & $(-0.44)$ \\
\hline High & $0.33(3.55)$ & $0.34(2.95)$ & -0.11 & $(-0.78)$ \\
\hline \multicolumn{5}{|l|}{ Employability (Unknown) } \\
\hline Bad & $-0.53(-5.95)$ & $0.15(0.67)$ & 1.06 & $(5.54)$ \\
\hline Medium & $-0.11(-1.20)$ & $0.12(0.77)$ & 0.74 & $(5.30)$ \\
\hline Good & 0.07 (1.02) & $0.37(1.94)$ & 0.61 & $(2.58)$ \\
\hline Looking for Other Occupation & $-0.09(-2.39)$ & $0.19(3.09)$ & 0.29 & $(1.72)$ \\
\hline \multicolumn{5}{|l|}{ Other Characteristics } \\
\hline \multicolumn{5}{|l|}{ Inflow Period (Dec 97) } \\
\hline Jan 98 & $0.08(1.54)$ & $-0.19(-2.82)$ & -0.11 & $(-0.73)$ \\
\hline Feb 98 & $0.08(1.67)$ & $-0.33(-2.09)$ & -0.63 & $(-2.41)$ \\
\hline March 98 & $0.07(1.09)$ & $-0.33(-1.78)$ & -0.20 & $(-0.86)$ \\
\hline \multicolumn{5}{|l|}{ Industry (Other Services) } \\
\hline Construction & $0.14(3.73)$ & $-0.19(-1.33)$ & -0.54 & $(-2.65)$ \\
\hline Tourism & $0.12(1.51)$ & $0.27(1.67)$ & -0.53 & $(-1.28)$ \\
\hline Manufacturing & $0.05(1.43)$ & $-0.09(-0.73)$ & -0.32 & $(-2.22)$ \\
\hline Transport / Utilities & $0.16(2.14)$ & $-0.25(-1.34)$ & -0.36 & $(-1.13)$ \\
\hline Wholesale and Retail Trade & $0.02(0.40)$ & $0.17(1.66)$ & -0.27 & $(-2.11)$ \\
\hline Financial Services & $0.03(0.32)$ & $0.16(0.71)$ & -0.89 & $(-2.08)$ \\
\hline Entry from Nonemployment & $0.08(0.54)$ & $-0.04(-0.14)$ & 0.04 & $(0.10)$ \\
\hline \multicolumn{5}{|l|}{ Occupation (All Other) } \\
\hline Construction & $-0.01(-0.20)$ & $-0.46(-3.10)$ & 0.16 & $(0.70)$ \\
\hline Tourism & $0.04(0.27)$ & $-0.04(-0.19)$ & 0.28 & $(0.71)$ \\
\hline \multicolumn{5}{|l|}{ Urbanization (Village) } \\
\hline Small City & $-0.20(-3.88)$ & $0.19(1.69)$ & -0.12 & $(-0.64)$ \\
\hline Large City & $-0.24(-1.98)$ & $0.03(0.33)$ & -0.10 & $(-0.41)$ \\
\hline Log (Unemployment Rate in Canton) & $-0.43(-2.63)$ & $-0.37(-1.14)$ & 0.54 & $(0.72)$ \\
\hline Log (ALMP-Participation Rate in Canton) & $-0.08(-0.72)$ & $0.79(2.03)$ & 0.99 & $(2.20)$ \\
\hline Log (Percentage Votes for Benefit Cut in Canton) & $0.21(1.75)$ & $0.13(0.48)$ & 0.16 & $(0.39)$ \\
\hline \multirow{2}{*}{\multicolumn{5}{|c|}{$\begin{array}{l}\text { Earnings and Employment History } \\
\text { Previous Employment Spell }\end{array}$}} \\
\hline & & & & \\
\hline No Previous Job & $-0.18(-0.60)$ & $-2.13(-2.34)$ & -1.40 & $(-1.92)$ \\
\hline Wage & $0.24(3.67)$ & $0.19(2.10)$ & 0.04 & $(0.43)$ \\
\hline Wage Squared & $-0.03(-4.48)$ & $-0.01(-0.59)$ & -0.01 & $(-1.03)$ \\
\hline Duration of Last Employment Spell & $-0.02(-2.91)$ & $-0.01(-0.90)$ & -0.01 & $(-0.59)$ \\
\hline \multicolumn{5}{|l|}{ Recent Past: 1994 to 1997} \\
\hline No Job & $0.04(0.11)$ & $-0.45(-0.93)$ & -0.43 & $(-0.56)$ \\
\hline Mean Wage & $0.03(0.84)$ & $0.03(0.78)$ & 0.01 & $(0.11)$ \\
\hline Variance of Wages & $-0.23(-0.47)$ & $-0.24(-0.43)$ & 0.05 & $(0.05)$ \\
\hline Percentage Employed & $0.55(4.41)$ & $0.03(0.11)$ & 0.17 & $(0.74)$ \\
\hline Number of Employment Spells & $0.03(0.76)$ & $-0.12(-1.94)$ & 0.00 & $(-0.05)$ \\
\hline Percentage Unemployed & $-0.81(-3.67)$ & $-1.62(-3.94)$ & -0.55 & $(-1.12)$ \\
\hline Number of Unemployment Spells & $0.05(1.69)$ & $0.07(1.56)$ & 0.05 & $(0.66)$ \\
\hline
\end{tabular}


Table A2b. (continued)

\begin{tabular}{|c|c|c|c|}
\hline \multicolumn{4}{|l|}{ Distant Past: 1988 to 1994} \\
\hline No Job & $0.16(1.05)$ & $-0.15(-0.63)$ & $-0.42(-0.78)$ \\
\hline Mean Wage & $0.01(0.99)$ & $0.02(0.44)$ & $-0.11 \quad(-2.25)$ \\
\hline Individual Wage Variance & $0.75(2.60)$ & $0.10(0.17)$ & $-0.22(-0.28)$ \\
\hline Percentage Employed & $0.45(3.07)$ & $-0.24(-1.00)$ & $-0.54(-1.15)$ \\
\hline Number of Employment Spells & $-0.01(-0.52)$ & $-0.08(-2.18)$ & $-0.09(-1.76)$ \\
\hline Percentage Unemployed & $-1.77(-4.49)$ & $1.18(2.35)$ & $0.41(0.55)$ \\
\hline Number of Unemployment Spells & $0.03(0.78)$ & $0.04(0.86)$ & $0.02(0.26)$ \\
\hline \multicolumn{4}{|l|}{ Masspoints } \\
\hline$u^{a}, v^{a}, w^{a}$ & $-4.05(-5.42)$ & $-2.32(-2.15)$ & $-4.01 \quad(-1.98)$ \\
\hline$u^{b}, v^{b}, w^{b}$ & $-3.45(-4.26)$ & $-5.98(-3.70)$ & -inf $(-)$ \\
\hline \multicolumn{4}{|l|}{ Duration Dependence (0 to 3 Months) } \\
\hline 3 to 6 Months & $0.42(4.58)$ & $0.01(0.07)$ & $0.56(2.55)$ \\
\hline 6 to 12 Months & $-0.14(-1.48)$ & $-0.66(-4.10)$ & $0.16(0.89)$ \\
\hline 12 to 18 Months & $-0.67(-6.44)$ & $-0.95(-3.19)$ & $-0.56(-1.95)$ \\
\hline \multicolumn{4}{|c|}{ Effect of unconditional Benefit Exhaustion } \\
\hline 1 to 0 Months before Exhaustion & $0.16(2.37)$ & $0.17(0.85)$ & $0.35(0.98)$ \\
\hline 0 to 1 Months after Exhaustion & $0.15(1.79)$ & $0.39(2.24)$ & $0.80(4.07)$ \\
\hline 1 and more Months after Exhaustion & $0.31(7.67)$ & $0.44(4.04)$ & 0.64 (3.39) \\
\hline \multicolumn{4}{|l|}{ Effect of ALMP during Participation } \\
\hline Basic Course & $-0.69(-2.74)$ & & \\
\hline Language Course & $-0.67(-2.89)$ & & \\
\hline Computer Course & $-0.75(-2.53)$ & & \\
\hline Other Course & $-0.81(-4.03)$ & & \\
\hline Employment Programme & $-0.86(-5.84)$ & & \\
\hline \multicolumn{4}{|l|}{ Effect of ALMP after Participation } \\
\hline Basic Course & $0.14(1.36)$ & & \\
\hline Language Course & $0.28(1.14)$ & & \\
\hline Computer Course & $0.25(2.06)$ & & \\
\hline Other Course & $0.29(2.38)$ & & \\
\hline Employment Programme & $0.34(1.52)$ & & \\
\hline $\operatorname{Prob}\left(u=u^{a}, v=v^{a}, w=w^{a}\right)$ & $0.77(12.51)$ & & \\
\hline $\operatorname{Prob}\left(u=u^{a}, v=v^{b}, w=w^{b}\right)$ & $0.00(-)$ & & \\
\hline $\operatorname{Prob}\left(u=u^{b}, v=v^{a}, w=w^{a}\right)$ & $0.00(-)$ & & \\
\hline $\operatorname{Prob}\left(u=u^{b}, v=v^{b}, w=w^{b}\right)$ & $0.23(-)$ & & \\
\hline log Likelihood & -17270.2 & & \\
\hline Number of Observations & 7477 & & \\
\hline
\end{tabular}

Note: t-Values in parentheses. 
Table A3a. The effect of ALMPs and Benefit Exhaustion, Females, no Heterogeneity

TO JOB TO COURSE TO EMPL. PROG.

\begin{tabular}{|c|c|c|c|c|}
\hline \multicolumn{5}{|l|}{ Individual Characteristics } \\
\hline Married & $-0.06(-0.67)$ & $0.03(0.32)$ & 0.14 & $(0.69)$ \\
\hline Number of Dep. & $-0.12(-2.94)$ & $0.06(1.03)$ & -0.07 & $(-0.92)$ \\
\hline \multicolumn{5}{|l|}{ Age (16 to 30$)$} \\
\hline 30 to 50 & $-0.24(-3.02)$ & $0.27(3.26)$ & -0.19 & $(-1.35)$ \\
\hline 50 to 65 & $-0.68(-6.38)$ & $0.04(0.23)$ & 0.11 & $(0.35)$ \\
\hline \multicolumn{5}{|l|}{ Skill Level (Unskilled) } \\
\hline Medium & $0.10(0.78)$ & $0.18(1.15)$ & 0.23 & $(1.00)$ \\
\hline High & $0.42(3.87)$ & $0.26(2.92)$ & 0.07 & $(0.34)$ \\
\hline \multicolumn{5}{|l|}{ Employability (Unknown) } \\
\hline Bad & $-0.26(-1.68)$ & $-0.40(-2.13)$ & -0.03 & $(-0.07)$ \\
\hline Medium & $0.03(0.34)$ & $-0.09(-0.75)$ & 0.31 & $(1.07)$ \\
\hline Good & $0.17(1.70)$ & $-0.06(-0.51)$ & 0.33 & $(1.15)$ \\
\hline Looking for Other Occupation & $-0.24(-4.04)$ & $0.16(2.31)$ & 0.40 & $(2.50)$ \\
\hline \multicolumn{5}{|l|}{ Other Characteristics } \\
\hline \multicolumn{5}{|l|}{ Inflow Period (Dec 97) } \\
\hline Jan 98 & $-0.04(-0.59)$ & $-0.14(-1.39)$ & -0.02 & $(-0.11)$ \\
\hline Feb 98 & $0.01(0.17)$ & $-0.25(-1.67)$ & -0.14 & $(-0.57)$ \\
\hline March 98 & $-0.04(-0.61)$ & $-0.24(-1.85)$ & -0.55 & $(-2.09)$ \\
\hline \multicolumn{5}{|l|}{ Industry (Other Services) } \\
\hline Construction & $-0.10(-1.10)$ & $0.23(1.10)$ & -0.13 & $(-0.31)$ \\
\hline Tourism & $0.20(2.39)$ & $0.04(0.35)$ & -0.71 & $(-3.36)$ \\
\hline Manufacturing & $-0.07(-0.78)$ & $0.11(1.05)$ & -0.26 & $(-1.12)$ \\
\hline Transport / Utilities & $0.08(0.75)$ & $0.36(1.56)$ & -0.06 & $(-0.16)$ \\
\hline Wholesale and Retail Trade & $0.05(0.84)$ & $0.15(1.45)$ & -0.57 & $(-2.15)$ \\
\hline Financial Services & $0.18(1.78)$ & $0.40(2.79)$ & -0.17 & $(-0.47)$ \\
\hline Entry from Nonemployment & $-0.30(-2.17)$ & $-0.15(-1.04)$ & -0.15 & $(-0.61)$ \\
\hline \multicolumn{5}{|l|}{ Occupation (All Other) } \\
\hline Tourism & $-0.07(-0.65)$ & $-0.01(-0.06)$ & -0.01 & $(-0.05)$ \\
\hline \multicolumn{5}{|l|}{ Urbanization (Village) } \\
\hline Small City & $-0.13(-2.22)$ & $0.18(1.76)$ & -0.07 & $(-0.44)$ \\
\hline Large City & $-0.18(-1.82)$ & $0.09(0.99)$ & 0.18 & $(0.82)$ \\
\hline Log (Unemployment Rate in Canton) & $-0.44(-3.52)$ & $0.38(1.04)$ & 0.23 & $(0.54)$ \\
\hline Log (ALMP-Participation Rate in Canton) & $0.00(0.03)$ & $0.77(2.47)$ & 1.23 & $(3.01)$ \\
\hline Log (Percentage Votes for Benefit Cut in Canton) & $0.20(1.78)$ & $0.25(1.19)$ & -0.29 & $(-0.92)$ \\
\hline \multirow{2}{*}{\multicolumn{5}{|c|}{$\begin{array}{l}\text { Earnings and Employment History } \\
\text { Previous Employment Spell }\end{array}$}} \\
\hline & & & & \\
\hline Wage & $0.18(2.41)$ & $0.26(4.76)$ & 0.57 & $(2.89)$ \\
\hline Wage Squared & $-0.03(-2.91)$ & $-0.01(-2.72)$ & -0.06 & $(-2.36)$ \\
\hline Duration of Last Employment Spell & $-0.03(-1.77)$ & $0.00(0.13)$ & 0.03 & $(0.70)$ \\
\hline \multicolumn{5}{|l|}{ Recent Past: 1994 to 1997} \\
\hline No Job & $-0.14(-0.49)$ & $0.06(0.17)$ & -0.36 & $(-0.74)$ \\
\hline Mean Wage & $0.03(1.07)$ & $-0.02(-0.41)$ & -0.23 & $(-2.41)$ \\
\hline Variance of Wages & $-0.58(-2.00)$ & $-0.33(-0.56)$ & -2.76 & $(-1.84)$ \\
\hline Percentage Employed & $0.09(0.74)$ & $0.49(2.21)$ & 0.30 & $(0.67)$ \\
\hline Number of Employment Spells & $-0.03(-0.77)$ & $-0.03(-0.61)$ & 0.08 & $(0.62)$ \\
\hline Percentage Unemployed & $-0.39(-1.75)$ & $-0.55(-1.15)$ & -1.04 & $(-1.17)$ \\
\hline Number of Unemployment Spells & $-0.05(-1.31)$ & $-0.03(-0.67)$ & 0.10 & $(1.34)$ \\
\hline
\end{tabular}


Table A3a. (continued)

\begin{tabular}{|c|c|c|c|}
\hline \multicolumn{4}{|l|}{ Distant Past: 1988 to 1994} \\
\hline No Job & $0.27(1.77)$ & $-0.35(-0.90)$ & $-0.71(-1.45)$ \\
\hline Mean Wage & $0.02(0.54)$ & $0.01(0.46)$ & $-0.08(-1.06)$ \\
\hline Individual Wage Variance & $0.12(0.33)$ & $-1.35(-1.96)$ & $-1.11 \quad(-0.69)$ \\
\hline Percentage Employed & $0.26(1.59)$ & $-0.47(-1.82)$ & $-0.56(-1.13)$ \\
\hline Number of Employment Spells & $0.01(0.41)$ & $-0.02(-0.55)$ & $-0.09(-1.43)$ \\
\hline Percentage Unemployed & $-1.12(-2.83)$ & $0.83(1.53)$ & $-0.47 \quad(-0.47)$ \\
\hline Number of Unemployment Spells & $0.01(0.19)$ & $-0.06(-0.91)$ & $0.13(1.12)$ \\
\hline \multicolumn{4}{|l|}{ Masspoints } \\
\hline$u^{a}, v^{a}, w^{a}$ & $-2.60(-3.94)$ & $-4.07(-3.60)$ & $-1.99(-1.20)$ \\
\hline \multicolumn{4}{|l|}{ Duration Dependence (0 to 3 Months) } \\
\hline 3 to 6 Months & $0.01(0.10)$ & $0.04(0.29)$ & $0.43(2.71)$ \\
\hline 6 to 12 Months & $-0.51(-4.87)$ & $-0.81(-4.97)$ & $-0.18 \quad(-0.77)$ \\
\hline 12 to 18 Months & $-0.94(-3.99)$ & $-0.64(-2.20)$ & $-1.20(-2.54)$ \\
\hline \multicolumn{4}{|c|}{ Effect of unconditional Benefit Exhaustion } \\
\hline 1 to 0 Months before Exhaustion & $0.03(0.21)$ & $-0.07(-0.35)$ & $0.49(2.36)$ \\
\hline 0 to 1 Months after Exhaustion & $0.26(2.15)$ & $0.62(4.13)$ & $0.42(1.94)$ \\
\hline 1 and more Months after Exhaustion & $0.22(2.84)$ & $0.27(2.27)$ & $0.79(3.92)$ \\
\hline \multicolumn{4}{|l|}{ Effect of ALMP during Participation } \\
\hline Basic Course & $-0.62(-2.23)$ & & \\
\hline Language Course & $-1.09(-2.92)$ & & \\
\hline Computer Course & $-0.30(-1.04)$ & & \\
\hline Other Course & $-1.01(-2.19)$ & & \\
\hline Employment Programme & $-0.53(-3.05)$ & & \\
\hline \multicolumn{4}{|l|}{ Effect of ALMP after Participation } \\
\hline Basic Course & $0.25(2.32)$ & & \\
\hline Language Course & $0.03(0.12)$ & & \\
\hline Computer Course & $0.37(2.73)$ & & \\
\hline Other Course & $0.48(2.18)$ & & \\
\hline Employment Programme & $0.63(3.31)$ & & \\
\hline log Likelihood & -9211.7 & & \\
\hline Number of Observations & 3686 & & \\
\hline
\end{tabular}

Note: t-Values in parentheses. 
Table A3b. The effect of ALMPs and Benefit Exhaustion, Females, with correlated Heterogeneity

TO JOB TO COURSE TO EMPL. PROG.

\begin{tabular}{|c|c|c|c|c|}
\hline \multicolumn{5}{|l|}{ Individual Characteristics } \\
\hline Married & -0.05 & $(-0.49)$ & $0.03(0.33)$ & $0.06(0.20)$ \\
\hline Number of Dep. & -0.14 & $(-2.56)$ & $0.06(1.04)$ & $-0.07(-0.46)$ \\
\hline \multicolumn{5}{|l|}{ Age (16 to 30$)$} \\
\hline 30 to 50 & -0.24 & $(-2.84)$ & $0.27(3.25)$ & $-0.28(-1.52)$ \\
\hline 50 to 65 & -0.70 & $(-6.00)$ & $0.03(0.24)$ & $0.16(0.43)$ \\
\hline \multicolumn{5}{|l|}{ Skill Level (Unskilled) } \\
\hline Medium & 0.15 & $(1.14)$ & $0.19(1.12)$ & $-0.29(-0.76)$ \\
\hline High & 0.44 & (3.84) & $0.26(2.92)$ & $-0.20(-0.62)$ \\
\hline \multicolumn{5}{|l|}{ Employability (Unknown) } \\
\hline $\mathrm{Bad}$ & -0.29 & $(-1.71)$ & $-0.40(-2.12)$ & $0.49(0.72)$ \\
\hline Medium & 0.00 & $(-0.00)$ & $-0.09(-0.81)$ & $0.60(1.80)$ \\
\hline Good & 0.19 & $(1.57)$ & $-0.06(-0.50)$ & $0.37(0.93)$ \\
\hline Looking for Other Occupation & -0.25 & $(-3.63)$ & $0.16(2.31)$ & $0.46(1.72)$ \\
\hline \multicolumn{5}{|l|}{ Other Characteristics } \\
\hline \multicolumn{5}{|l|}{ Inflow Period (Dec 97) } \\
\hline Jan 98 & -0.06 & $(-0.77)$ & $-0.15(-1.34)$ & $0.23(0.54)$ \\
\hline Feb 98 & 0.02 & $(0.22)$ & $-0.25(-1.68)$ & $-0.13(-0.24)$ \\
\hline March 98 & -0.04 & $(-0.51)$ & $-0.24(-1.83)$ & $-0.72(-1.82)$ \\
\hline \multicolumn{5}{|l|}{ Industry (Other Services) } \\
\hline Construction & -0.10 & $(-0.85)$ & $0.23(1.12)$ & $0.41(0.67)$ \\
\hline Tourism & 0.23 & $(2.78)$ & $0.04(0.36)$ & $-1.14(-3.64)$ \\
\hline Manufacturing & -0.02 & $(-0.21)$ & $0.11(1.04)$ & $-0.43(-2.43)$ \\
\hline Transport / Utilities & 0.08 & $(0.68)$ & $0.36(1.56)$ & $-0.54(-1.02)$ \\
\hline Wholesale and Retail Trade & 0.09 & $(1.33)$ & $0.15(1.52)$ & $-0.88(-2.14)$ \\
\hline Financial Services & 0.20 & $(1.90)$ & $0.40(2.65)$ & $-0.25(-0.39)$ \\
\hline Entry from Nonemployment & -0.30 & $(-2.21)$ & $-0.15(-1.04)$ & $-0.34(-0.92)$ \\
\hline \multicolumn{5}{|l|}{ Occupation (All Other) } \\
\hline Tourism & -0.08 & $(-0.66)$ & $-0.01(-0.05)$ & $0.01(0.04)$ \\
\hline \multicolumn{5}{|l|}{ Urbanization (Village) } \\
\hline Small City & -0.14 & $(-2.21)$ & $0.18(1.78)$ & $0.01(0.04)$ \\
\hline Large City & -0.18 & $(-1.56)$ & $0.09(0.99)$ & $0.16(0.57)$ \\
\hline Log (Unemployment Rate in Canton) & -0.48 & $(-3.57)$ & $0.39(1.04)$ & $-0.20(-0.24)$ \\
\hline Log (ALMP-Participation Rate in Canton) & 0.01 & $(0.06)$ & $0.77(2.39)$ & $0.93(1.13)$ \\
\hline Log (Percentage Votes for Benefit Cut in Canton) & 0.24 & $(2.17)$ & $0.25(1.20)$ & $-0.79(-1.21)$ \\
\hline \multirow{2}{*}{\multicolumn{5}{|c|}{$\begin{array}{l}\text { Earnings and Employment History } \\
\text { Previous Employment Spell }\end{array}$}} \\
\hline & & & & \\
\hline \multicolumn{5}{|l|}{ Wage } \\
\hline Wage Squared & 0.19 & $(2.31)$ & $0.26(4.71)$ & $0.42(1.61)$ \\
\hline Duration of Last Employment Spell & -0.03 & $(-2.64)$ & $-0.01(-2.68)$ & $-0.04(-1.24)$ \\
\hline Recent Past: 1994 to 1997 & -0.03 & $(-1.85)$ & $0.00(0.12)$ & $0.05(1.01)$ \\
\hline No Job & -0.20 & $(-0.73)$ & $0.06(0.16)$ & $0.72(1.50)$ \\
\hline Mean Wage & 0.03 & $(1.25)$ & $-0.02(-0.42)$ & $-0.26(-2.29)$ \\
\hline Variance of Wages & -0.68 & $(-2.13)$ & $-0.33(-0.57)$ & $-2.72(-1.11)$ \\
\hline Percentage Employed & 0.05 & $(0.37)$ & $0.49(2.20)$ & $1.03(1.75)$ \\
\hline Number of Employment Spells & -0.05 & $(-1.08)$ & $-0.03(-0.61)$ & $0.24(1.57)$ \\
\hline Percentage Unemployed & -0.48 & $(-1.76)$ & $-0.55(-1.14)$ & $-0.52(-0.83)$ \\
\hline Number of Unemployment Spells & -0.04 & $(-0.69)$ & $-0.03(-0.65)$ & $0.11(0.88)$ \\
\hline
\end{tabular}


Table A3b. (Continued)

\begin{tabular}{|c|c|c|c|c|}
\hline \multicolumn{5}{|l|}{ Distant Past: 1988 to 1994} \\
\hline No Job & 0.24 & $(1.37)$ & $-0.35(-0.91)$ & $-0.92(-1.18)$ \\
\hline Mean Wage & 0.02 & $(0.66)$ & $0.01(0.46)$ & $-0.09(-0.96)$ \\
\hline Individual Wage Variance & 0.16 & $(0.44)$ & $-1.34(-1.90)$ & $-1.30(-0.61)$ \\
\hline Percentage Employed & 0.26 & $(1.44)$ & $-0.47(-1.82)$ & $-0.92(-2.42)$ \\
\hline Number of Employment Spells & 0.01 & $(0.56)$ & $-0.02(-0.54)$ & $-0.20(-1.81)$ \\
\hline Percentage Unemployed & -1.25 & $(-2.87)$ & $0.83(1.52)$ & $-0.06(-0.04)$ \\
\hline Number of Unemployment Spells & 0.02 & $(0.39)$ & $-0.06(-0.91)$ & $0.12(0.69)$ \\
\hline \multicolumn{5}{|l|}{ Masspoints } \\
\hline$u^{a}, v_{c}^{a}, v_{e}^{a}$ & -4.07 & $(-3.74)$ & $-4.12(-3.55)$ & $1.76(0.59)$ \\
\hline$u^{b}, v_{c}^{b}, v_{e}^{b}$ & -2.47 & $(-3.58)$ & $-4.06(-3.55)$ & $-\inf \quad(-)$ \\
\hline \multicolumn{5}{|l|}{ Duration Dependence (0 to 3 Months) } \\
\hline 3 to 6 Months & 0.04 & $(0.50)$ & $0.05(0.29)$ & $0.51(2.23)$ \\
\hline 6 to 12 Months & -0.44 & $(-2.75)$ & $-0.80(-4.90)$ & $-0.08(-0.18)$ \\
\hline 12 to 18 Months & -0.86 & $(-3.04)$ & $-0.64(-2.16)$ & $-0.94(-1.39)$ \\
\hline \multicolumn{5}{|c|}{ Effect of unconditional Benefit Exhaustion } \\
\hline 1 to 0 Months before Exhaustion & 0.02 & $(0.16)$ & $-0.07(-0.35)$ & $0.53(1.88)$ \\
\hline 0 to 1 Months after Exhaustion & 0.26 & $(2.06)$ & $0.62(4.08)$ & $0.60(2.22)$ \\
\hline 1 and more Months after Exhaustion & 0.19 & $(2.12)$ & $0.26(2.34)$ & $1.46(4.33)$ \\
\hline \multicolumn{5}{|l|}{ Effect of ALMP during Participation } \\
\hline Basic Course & -0.63 & $(-2.21)$ & & \\
\hline Language Course & -1.09 & $(-2.99)$ & & \\
\hline Computer Course & -0.31 & $(-1.09)$ & & \\
\hline Other Course & -0.98 & $(-2.12)$ & & \\
\hline Employment Programme & 0.89 & $(0.75)$ & & \\
\hline \multicolumn{5}{|l|}{ Effect of ALMP after Participation } \\
\hline Basic Course & 0.27 & $(1.62)$ & & \\
\hline Language Course & 0.03 & $(0.12)$ & & \\
\hline Computer Course & 0.45 & $(2.74)$ & & \\
\hline Other Course & 0.64 & $(1.70)$ & & \\
\hline Employment Programme & 2.05 & $(1.68)$ & & \\
\hline $\operatorname{Prob}\left(u=u^{a}, v_{c}=v_{c}^{a}, v_{e}=v_{e}{ }^{a}\right)$ & 0.18 & $(3.40)$ & & \\
\hline $\operatorname{Prob}\left(u=u^{a}, v_{c}=v_{c}^{b}, v_{e}=v_{e}^{b}\right)$ & 0.00 & $(-)$ & & \\
\hline $\operatorname{Prob}\left(u=u^{b}, v_{c}=v_{c}^{a}, v_{e}=v_{e}{ }^{a}\right)$ & 0.00 & $(-)$ & & \\
\hline $\operatorname{Prob}\left(u=u^{b}, v_{c}=v_{c}^{b}, v_{e}=v_{e}^{b}\right)$ & 0.82 & $(-)$ & & \\
\hline $\begin{array}{l}\text { log Likelihood } \\
\text { Number of Observations }\end{array}$ & $\begin{array}{r}-9202.9 \\
3686\end{array}$ & & & \\
\hline
\end{tabular}

Note: t-Values in parentheses. 
Table A4. Definition of variables.

\begin{tabular}{ll} 
Unemployment Spell & \\
\hline Elapsed Duration & time from registering unemployed until transition to job or censoring \\
\hline Exit to Job & Exit to paid employment in first labor market. \\
\hline Unconditional Benefit Eligibility at Start & 150 work days (approx. 7 months) for individuals younger than 50 years. \\
& 250 work days (approx. 11.5 months) for individuals between 50 and 60 years \\
& 400 work days (approx. 18.5 months) for individuals older than 60. \\
shorter for those repeatedly unemployed within same framework period \\
see text.
\end{tabular}

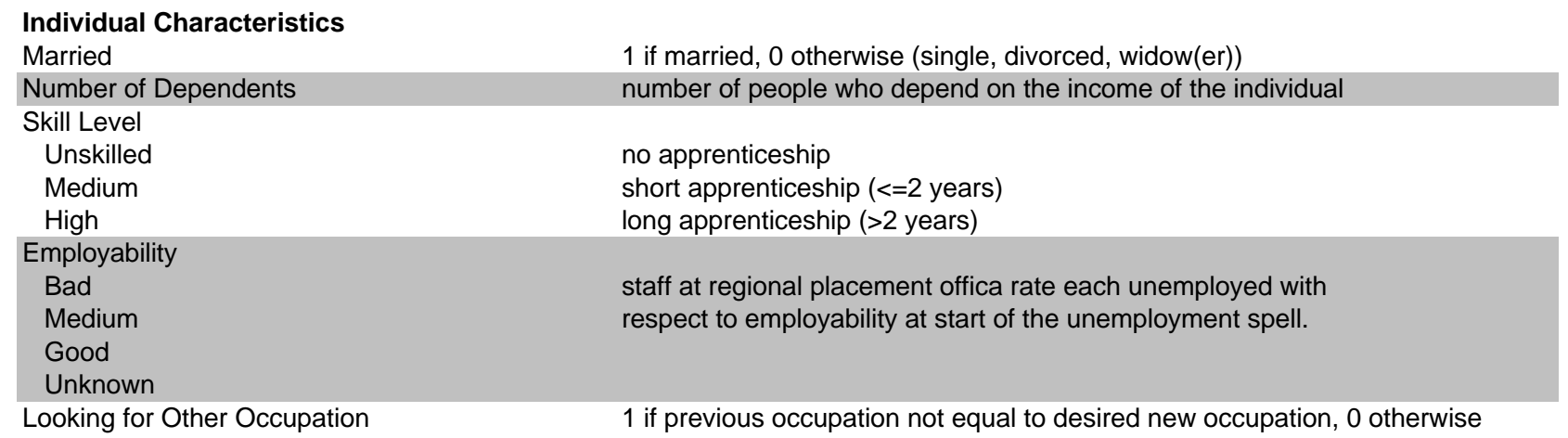

\section{Other Characteristics}

Urbanization
Village
Small City
Large City

City of residence has

less than 10,000 inhabitants

between 10,000 and 100,000 inhabitants

more than 100,000 inhabitants

Log (Unemployment Rate in Canton)

unemployment rate at start of unemployment spell

Log (ALMP-Participation Rate in Canton)

number of unemployed in ALMP divided by number of unemployed at start of unemployment spell

Log (Percentage Votes for Benefit Cut in Canton) percentage voting for a cut in unemployment benefits of 1 to $3 \%$, national referendum held on 28 Sept. 1997.

\begin{tabular}{|c|c|}
\hline \multicolumn{2}{|l|}{$\begin{array}{l}\text { Earnings and Employment History } \\
\text { Previous Employment Spell }\end{array}$} \\
\hline No Previous Job & Previous wage is zero \\
\hline Wage & Wage in previous job, in SFR (1 SFR=.75 USD in 1997), divided by 1000. \\
\hline Duration of previous Employment Spell & Duration of previous employment spell, period 1988-1997, in years. \\
\hline \multicolumn{2}{|l|}{ Recent Past: 1995 to 1997} \\
\hline No Job & Mean wage is zero, $1995-1997$ \\
\hline Mean Wage & Mean wage, in SFR (1 SFR=.75 USD in 1997), divided by 1000, 1995 to 1997. \\
\hline Variance of Wages & Variance of individual earnings, weighted by duration of job, 1995-1997. \\
\hline Percentage Employed & employment duration divided by total time in labor force, 1995-1997. \\
\hline Number of Employment Spells & number of employment spells, 1995-1997. \\
\hline Percentage Unemployed & unemployment duration divided by total time in labor force, 1995-1997. \\
\hline Number of Unemployment Spells & number of unemployment spells, 1995-1997. \\
\hline \multicolumn{2}{|l|}{ Distant Past: 1988 to 1994} \\
\hline No Job & Mean wage is zero, $1988-1994$ \\
\hline Mean Wage & Mean wage, in SFR (1 SFR=.75 USD in 1997), divided by 1000, 1995 to 1997. \\
\hline Individual Wage Variance & Variance of individual earnings, weighted by duration of job, 1988-1994. \\
\hline Percentage Employed & employment duration divided by total time in labor force, $1988-1994$. \\
\hline Number of Employment Spells & number of employment spells, $1988-1994$. \\
\hline Percentage Unemployed & unemployment duration divided by total time in labor force, $1988-1994$. \\
\hline Number of Unemployment Spells & number of unemployment spells, 1988-1994. \\
\hline
\end{tabular}




\section{IZA Discussion Papers}

No. Author(s)

51

A. Barrett

P. J. O'Connell

52 J. Mayer

R. T. Riphahn

53

J. Hartog

P. T. Pereira

J. A. C. Vieira

54 M. Lofstrom

55

L. Goerke

56

A. Lindbeck

D. J. Snower

57

I. N. Gang

K. F. Zimmermann

58

T. Bauer

K. F. Zimmermann

59

D. J. DeVoretz

S. A. Laryea

60

C. Belzil

J. Hansen

61

R. Winkelmann

62

A. Thalmaier

63

M. Ward

64

M. Ward

65

H. Lehmann

J. Wadsworth

A. Acquisti

66

E. J. Bird

H. Kayser

J. R. Frick

G. G. Wagner
Title

Area

Date

Does Training Generally Work?

5

$8 / 99$

The Returns to In-Company Training

Fertility Assimilation of Immigrants: Evidence

3

$8 / 99$

from Count Data Models

Inter-industry Wage Dispersion in Portugal: high

but falling

$8 / 99$

Labor Market Assimilation and the

$8 / 99$

Self-Employment Decision of Immigrant

Entrepreneurs

Value-added Tax versus Social Security

Contributions

Centralized Bargaining and Reorganized Work:

Are they compatible?

Is Child like Parent?

Educational Attainment and Ethnic Origin

9/99

Occupational Mobility of Ethnic Migrants

$9 / 99$

Canadian Immigration Experience:

Any Lessons for Europe?

Subjective Discount Rates, Intergenerational

Transfers and the Return to Schooling

Immigration: The New Zealand Experience

$10 / 99$

Bestimmungsgründe von Fehlzeiten: Welche

Rolle spielt die Arbeitslosigkeit?

1/2/3 9/99

6

$10 / 99$

Your Everyday, Average Academic

$10 / 99$

Salary and the Gender Salary Gap in the Academic Profession

Grime and Punishment: Job Insecurity and Wage 4

Arrears in the Russian Federation

$10 / 99$

The Immigrant Welfare Effect: Take-Up or

3

$10 / 99$ 

of Wage Differentials Transition Economies

\section{0 \\ J. C. van Ours}

J. Veenman
The Netherlands: Old Emigrants - Young Immigrant Country

Migration, Migrants and Policy in the United Kingdom

Privacy, time consistent optimal labor income taxation and education policy

Female Labour Supply, Flexibility of Working Hours, 1 and Job Mobility in the Netherlands

The Heterogeneity and Cyclical Sensitivity of 1 Unemployment: An Exploration of German Labor Market Flows 

Adversity

91 M. Lechner

Tenures that Shook the World: Worker Turnover in $\quad 4$ Russia, Poland and Britain

Identification and Estimation of Causal Effects of

An Evaluation of Public-Sector-Sponsored

Continuous Vocational Training Programs in East

N. Smith 
107 J. C. van Ours G. Ridder

J. Boone

J. C. van Ours

109 G. J. van den Berg

B. van der Klaauw

110 D. DeVoretz

C. Werner

111 V. Sorm

K. Terrell

L. Bellmann

T. Schank

113 R. Euwals

114 G. Brunello

A. Medio

115 A. Cigno

F. C. Rosati

116

C. Belzil

A. Haas

C. Klose

118 M. A. Shields

M. E. Ward

119 A. Lindbeck

D. J. Snower

120 P. T. Pereira

P. S. Martins

121 J. C. van Ours
Fast Track or Failure: A Study of the Completion

Rates of Graduate Students in Economics

Modeling Financial Incentives to Get Unemployed Back to Work

Combining Micro and Macro Unemployment

3

$1 / 00$

Duration Data

A Theory of Social Forces and Immigrant Second

1

$2 / 00$

Language Acquisition

Sectoral Restructuring and Labor Mobility:

A Comparative Look at the Czech Republic

Innovations, Wages and Demand for

5

$2 / 00$

Heterogeneous Labour: New Evidence from a

Matched Employer-Employee Data-Set

Do Mandatory Pensions Decrease Household

Savings? Evidence for the Netherlands

An Explanation of International Differences in

Education and Workplace Training

Why do Indian Children Work, and is it Bad for

3

$2 / 00$

Them?

Unemployment Insurance and Subsequent Job

3

$2 / 00$

Duration: Job Matching vs. Unobserved

Heterogeneity

IAB Employment Subsample 1975-1995.

Opportunities for Analysis Provided by the

Anonymised Subsample

Improving Nurse Retention in the British National

5

$2 / 00$

Health Service: The Impact of Job Satisfaction on Intentions to Quit

The Division of Labor and the Market for

Organizations

Does Education Reduce Wage Inequality?

5

Quantile Regressions Evidence from Fifteen

European Countries

Do Active Labor Market Policies Help Unemployed Workers to Find and Keep Regular Jobs? 
Rational Poverty or Poor Rationality? The Take-up of Social Assistance Benefits

125 F. Büchel

The Income Portfolio of Immigrants in Germany -

Effects of Ethnic Origin and Assimilation. Or:

J. R. Frick

126 J. Fersterer

R. Winter-Ebmer

Who Gains from Income Re-Distribution?

127 M. Karanassou

D. J. Snower

Smoking, Discount Rates, and Returns to

Education

Characteristics of Unemployment Dynamics: The

Chain Reaction Approach

128 O. Ashenfelter

D. Ashmore

O. Deschênes

Do Unemployment Insurance Recipients Actively

Seek Work? Evidence From Randomized Trials in

Four U.S. States

129 B. R. Chiswick

M. E. Hurst

C. Lucifora

The Employment, Unemployment and Unemployment Compensation Benefits of Immigrants

The Returns to Education in Italy: A New Look at the Evidence

Are Immigrants Favorably Self-Selected? An

134 A. D. Kugler

G. Saint-Paul

135 A. Barrett P. J. O'Connell

136 M. Bräuninger M. Pannenberg

Is There a Wage Premium for Returning Irish

Unemployment and Productivity Growth: An

Empirical Analysis within the Augmented Solow 
141 R. Hujer

M. Wellner

142 J. J. Dolado

F. Felgueroso

J. F. Jimeno

143 P. J. Luke

M. E. Schaffer

144 G. Saint-Paul

145 M.-S. Yun

146 T. K. Bauer

J. P. Haisken-DeNew

147 M. Belot

J. C. van Ours

148 L. Goerke

149 R. Lalive

J. C. van Ours

J. Zweimüller
The Effects of Public Sector Sponsored Training on

Individual Employment Performance in East

Germany

Explaining Youth Labor Market Problems in Spain: 3

Crowding-Out, Institutions, or Technology Shifts?

Wage Determination in Russia: An Econometric 4

Investigation

Flexibility vs. Rigidity: Does Spain have the worst of 1 both Worlds?

Decomposition Analysis for a Binary Choice Model 7

Employer Learning and the Returns to Schooling

5

Does the Recent Success of Some OECD

Countries in Lowering their Unemployment Rates

Lie in the Clever Design of their Labour Market

Reforms?

Employment Effects of Labour Taxation in an Efficiency Wage Model with Alternative Budget Constraints and Time Horizons

The Impact of Active Labor Market Programs and Benefit Entitlement Rules on the Duration of Unemployment
$4 / 00$

$4 / 00$

$4 / 00$

$4 / 00$

$4 / 00$

$4 / 00$

$4 / 00$

$5 / 00$

$5 / 00$

An updated list of IZA Discussion Papers is available on the center's homepage www.iza.org. 